Research Article

\title{
Amplification Effect of Ground Motion in Offshore Meandering Sedimentary Valley
}

\author{
Hailiang Wang, ${ }^{1,2}$ Shaomin Yan $\mathbb{D}^{1,2}$ Zhongxian Liu $\mathbb{D}^{1,2}$ and Xinglei Cheng $\mathbb{D}^{2}$ \\ ${ }^{1}$ Tianjin Key Laboratory of Civil Building Structure Protection and Reinforcement, Tianjin Chengjian University, \\ Tianjin 300384, China \\ ${ }^{2}$ School of Civil Engineering, Tianjin Chengjian University, Tianjin 300384, China
}

Correspondence should be addressed to Zhongxian Liu; zhongxian1212@163.com

Received 18 June 2021; Accepted 9 September 2021; Published 28 October 2021

Academic Editor: Yu xiang Ma

Copyright ( $) 2021$ Hailiang Wang et al. This is an open access article distributed under the Creative Commons Attribution License, which permits unrestricted use, distribution, and reproduction in any medium, provided the original work is properly cited.

\begin{abstract}
A sedimentary valley has a visible amplification effect on a seismic response, and the current 2D topographies cannot truthfully reflect the twists and turns of a large-scale river valley. Taking a sinusoidal curved valley site as a model, the dynamic finite element analysis method and the introduction of a viscoelastic artificial boundary were developed to study the 3D seismic response of the dimensional topographies in the homogeneous curved valley to vertical incident $\mathrm{P}, \mathrm{SV}$, and SH waves. The results showed that the bending sedimentary valley site earthquake presented significant features simultaneously, depending on the number of valley bends, the frequency of the excitations, the shear wave velocity of sedimentary soil, and the depth of the river valley. The surface displacement amplitudes of three-dimensional meandering sedimentary valleys are significantly different from those of sedimentary basins. The amplification area of the meandering valley is related to the angle between the valley axis and wave vibration direction, and the amplification effect is significant when the angle is small. The movement in the main direction showed a center focus, and the secondary $y$-direction displacement showed both a central focus and an edge effect. When the frequency of the incident wave was close to the natural vibration frequency in a specific direction, the movement in this direction significantly increased because of the resonance effect. The displacement amplitude of the surface was proportional to the depth of the river valley, and the surface displacement was presented in different forms based on the frequency of the excitations. The results provided some guidance for the earthquake resistance of the curved valley site.
\end{abstract}

\section{Introduction}

There are many rivers in China, especially in the western region. Many important infrastructure projects such as dams and bridges have been built, under construction, and proposed in the valley site. However, China is a multiearthquake country and the western region is the main strong earthquake area in China; many of these large-scale projects are threatened by the potential earthquake. It is a major national demand to prevent and resolve the earthquake disaster risk of major projects in the valley site. The phenomenon of terrain effect has been confirmed by a large number of measured seismic records and observed earthquake damage [1-6]. Terrain effect is always an important wave problem in seismology, earthquake engineering, and civil engineering.
In addition to the amplification of ground motion, the valley topography can also cause the spatial variation of seismic ground motion within the local site. The peak value and phase of seismic waves at different locations are different. It can be seen that the valley terrain amplification effect has a direct impact on the rationality of the earthquake input in the seismic calculation of large-scale infrastructure projects in China, which will seriously affect the reliability of the seismic design of such projects.

Binhai New District in Tianjin is located in the east of North China Plain and west of Bohai Bay, with flat terrain and dense rivers; because of the influence of climate, paleogeography environment, neotectonic movement, and sealand changes, the river course has changed many times since the Late Pleistocene, and there are various scales of 
meandering ancient river course. The construction projects located on the ancient river course are more prone to earthquake damage. For example, during the 1976 earthquake of Tangshan, many abnormal areas of earthquake damage appeared in the ancient river channel area of Tianjin; the distribution characteristics of earthquake damage in these areas are that the collapse rate of buildings from the edge of the river valley to the center of the river valley is high, while the earthquake damage outside the river valley is light; it shows that the valley site can amplify the seismic wave. In recent years, with the rapid development of engineering construction in coastal areas, the adverse impact of ancient rivers on construction projects has become increasingly prominent.

Theoretical investigations have assisted in revealing the mechanisms of river valley topography effects. Beginning with the preliminary work on the response of a valley to $\mathrm{SH}$ waves, which was addressed by Aki and Larner [7], the methodologies can be divided into two categories: analytical and numerical. Some scholars have studied valley sites with analytical solutions [8-18]. The numerical analyses can be classified into three types: domain-type [19-24], boundarytype [25-33], and hybrid-type [34-37]. For a more comprehensive and extensive review of topographic effects, refer to Zhou [38].

Notably, the abovementioned studies all involved twodimensional (2D) valley topography. Previous studies have shown that there are significant differences between 3D scattering and 2D scattering $[39,40]$. In recent years, some scholars have begun to study the $2.5 \mathrm{D}$ model [41-45], which has been used to respond to three-dimensional ground motion. However, the $2.5 \mathrm{D}$ model still assumes that the valley section is the same and that there is no spatial change in the terrain. These studies belong to the category of the three-dimensional seismic analysis of two-dimensional topography. Obviously, it is difficult to use the $2.5 \mathrm{D}$ model to accurately reflect the ground motion law of a 3D meandering river valley. Similarly, some excellent $3 \mathrm{D}$ papers that reflect the real topography are worth mentioning [46-53], but they also fail to discuss the seismic characteristics of the meandering river valley topography. In reality, meandering river valley sites are universal in nature. Figures 1 and 2 are satellite images of the Seine River in France and the Haihe River in Tianjin, China. These satellite images show that the valley sites have the apparent characteristics of winding river valleys. A large number of river valleys can be described as having a serpentine shape. As far as we know, research on the seismic response of three-dimensional (3D) meandering valley sites has not yet been conducted.

To fully understand the law of the influence of $3 \mathrm{D}$ meandering river valley topography on a seismic dynamic response as well as to ensure the safety of major trans-valley projects under the threat of earthquakes, it is necessary to study the dynamic response law of meandering valley topography when seismic waves are incident. This is done to provide some guidance for the earthquake resistance of a meandering valley site.

Utilizing finite element analysis software, several largescale three-dimensional meandering river valley models have been established. In addition, viscoelastic artificial

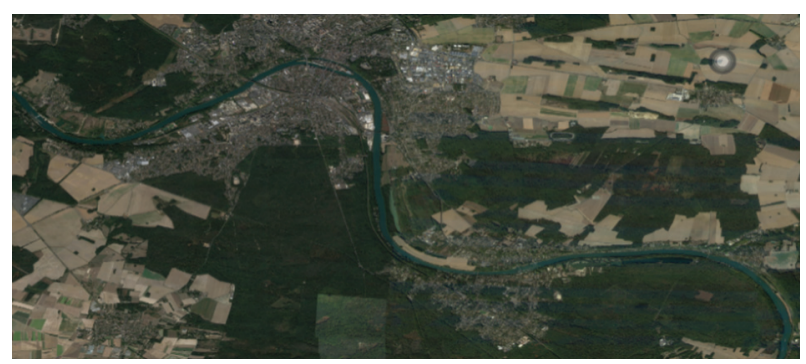

FIgURE 1: Satellite map of Seine River in France.

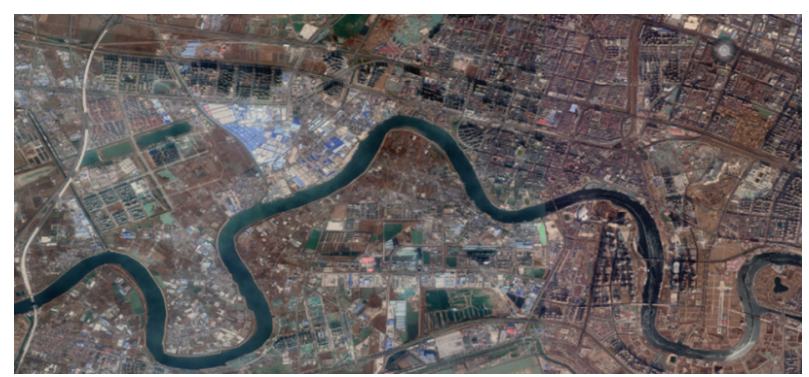

FIgURE 2: Satellite map of Haihe River in Tianjin, China.

boundaries have been introduced and three-dimensional homogeneous meandering depositional site models have been analyzed. Because there are more than ten million three-dimensional model units, calculations are relatively challenging to conduct. Therefore, this study introduced a harmonic response analysis to evaluate the frequency domain solution of a three-dimensional model. The equivalent load in the time domain was transformed into an equivalent load in the frequency domain using the fast Fourier transform, and the surface displacement of a meandering sedimentary valley site with an incident SV wave was analyzed.

The rest of the paper is organized as follows. The analysis model and research methods are presented in Section 2, which includes the introduction of the viscoelastic artificial boundaries, the derivation of the equivalent nodal force formula, and the opening of the time domain conversion in the frequency domain. In Section 3, the applicability of this method was verified using existing research. Section 4 discusses the numerical results in order to explore the effect of the depth of the deposition, the frequency of the incident wave, and multiple meandering sites. Section 5 describes several conclusions.

\section{Model and Methods}

2.1. Model. The seismic response of a three-dimensional model of a meandering sedimentary valley was investigated. For simplicity, the shape of the bend was simplified to a sine curve. Ten-node solid elements and twenty-node high-order solid elements were selected for the soil model. To satisfy an automatic infinity radiation condition, a viscoelastic artificial boundary was added around the overall model, and the viscouselastic artificial boundary was simulated with the axial spring-damper unit. 
Figure 3 is a schematic diagram of the model for a threedimensional (3D) homogeneous meandering sedimentary valley site. The calculation parameters were as follows: average shear wave velocity of the soil layer $C_{\mathrm{sv}}=500 \mathrm{~m} / \mathrm{s}$ (when analyzing the influencing factors of soil stiffness, CSV is taken as $C_{\mathrm{sv}}=300 \mathrm{~m} / \mathrm{s}, C_{\mathrm{sv}}=400 \mathrm{~m} / \mathrm{s}, C_{\mathrm{sv}}=500 \mathrm{~m} / \mathrm{s}$, and $C_{\mathrm{sv}}=600 \mathrm{~m} / \mathrm{s}$, respectively), density $\rho_{1}=1333 \mathrm{~kg} / \mathrm{m}^{3}$, Poisson's ratio, and viscous damping. The mean shear wave velocity of the bedrock in the meandering elastic half space was $C_{s}=1000 \mathrm{~m} / \mathrm{s}$, density $\rho_{0}=2000 \mathrm{~kg} / \mathrm{m}^{3}$, Poisson's ratio $v_{0}=0.25$, and viscous damping $\zeta_{1}=0.02$. The plane $\mathrm{P}, \mathrm{SV}$, and $\mathrm{SH}$ waves were incident perpendicularly from the bedrock bottom surface, $\zeta_{1}=0.05$, and the amplitude of the incident displacement of the $\mathrm{P}, \mathrm{SV}$, and $\mathrm{SH}$ waves was 1.0. The residual convergence was10-3. The truncated boundary size of the model is 4 times the site size of the meandering valley. The discrete finite element model is shown in Figure 4 (because of the large size of the model, only part of the finite element model of the intercepted cloud image is shown).

In order to fully display the manifestation of surface displacement of the meandering valley and its vicinity, the scope of the cloud image interception is only the result of cloud image near the meandering valley of the model. The model plane dimensions of the one meandering sedimentary valley model were $6800 \mathrm{~m} \times 3400 \mathrm{~m}$, the model plane dimensions of the two meandering sedimentary valley models were $9600 \mathrm{~m} \times 4800 \mathrm{~m}$, and the model plane dimensions of the three meandering sedimentary valley models were $12400 \mathrm{~m} \times 4800 \mathrm{~m}$. Using the two meandering sedimentary valleys as an example, the model plane dimensions are as shown in Figures 5 and 6.

2.2. The Viscoelastic Boundary. When simulating foundations, to eliminate the reflection of waves on the truncated boundary and reduce the degree of freedom of calculation, it was necessary to deal with the boundary of the local foundation. The method for dealing with this effect was to impose an artificial boundary on the truncated boundary. The types of artificial boundaries include Sommerfeld boundary [54], viscous boundary [55], superposition boundary [56, 57], paraxial approximation boundary [58-60], Higdon boundary [61], viscoelastic boundary [62-64], and transmitting artificial boundary [65]. The emergence of these boundaries has promoted the application of the finite element method in the seismic response of multiple sites. Li and song used a transmitting artificial boundary [66], and $\mathrm{Gu}$ et al. used viscoelastic boundaries to analyze a two-dimensional terrain seismic response [67]. Liu and $\mathrm{Li}$ [58] previously proposed a three-dimensional viscoelastic boundary based on two-dimensional viscoelastic boundaries. Liu et al. [59] recently analyzed the seismic response of reef construction sites based on viscoelastic artificial boundaries. Similarly, some recent papers also study site effects based on viscoelastic artificial boundaries $[60,68]$.The three-dimensional viscoelastic boundary construction and ground motion input technology referred to in this article approximate the realization of nonreflective boundary conditions by setting spring and damping elements along the three-axis axis at the unit node at the truncated boundary. In ANSYS software, the COMBIN14 spring element was used for simulation. The normal and tangential damping coefficient and the spring stiffness at the nodes were as follows:

$$
\begin{aligned}
& K_{b n}=\alpha_{n} \frac{G}{R} A_{b}, \\
& C_{b n}=\rho c_{p} A_{b}, \\
& K_{b t}=\alpha_{t} \frac{G}{R} A_{b}, \\
& C_{b t}=\rho c_{s} A_{b},
\end{aligned}
$$

where $K_{b n}, K_{b t}, C_{b n}$, and $C_{b t}$ are the damping coefficients and the spring stiffnesses of the normal artificial boundary and the tangential artificial boundary. $G$ is the shear modulus of the elastic layer, $A_{b}$ is the influence area of the boundary node, $\rho$ is the mass density, $\alpha_{n}$ and $\alpha_{t}$ are the correction factors of the reasonable and tangential springs, respectively, $R$ is the distance from the scattered wave source of the artificial boundary node, and $c_{p}$ and $c_{s}$ are the $\mathrm{P}$-wave and s-wave velocities, respectively. The recommended values that were given in the literature [58] were used in this study. $\alpha_{n}=1.33$ with $\alpha_{t}=0.67$. This value was obtained through programming with the software APDL (ANSYS Parameter Design Language).

\subsection{Simplified Method for Inputting the Ground Motion.} When the viscoelastic boundary completely absorbed the externally transmitted, scattered waves in the calculation area, the problem of free field motion at the artificial boundary node could be converted into the equivalent node force at the artificial boundary node.

The displacement vector of the free field of the artificial boundary node was defined as $u_{b_{T}}^{f f}=\left[\begin{array}{lll}u & v & w\end{array}\right]^{T}$. The velocity vector was $u_{b}^{f f}=\left[\begin{array}{lll}u & \dot{v} & \dot{w}\end{array}\right]^{T}$, the stress tensor was $\sigma_{b}^{f f}$, the spring stiffness coefficient of the viscoelastic boundary was $K_{b}$, and the damping coefficient was $C_{b}$. It was repeatedly deduced that the equivalent node force acting on the artificial boundary node was

$$
F_{b}=\left(K_{b} u_{b}^{f f}+C_{b} u_{b}^{f f}+\sigma_{b}^{f f} n\right) A_{b},
$$

where $A_{b}$ is the influence area of the boundary node, $n$ is the cosine vector of the direction of the normal outside the boundary, and $K_{b}$ is a $3 \times 3$ diagonal array. The boundary surface and its form were different. When the normal course of the boundary surface was parallel to the $x$-axis, it was $\left[\begin{array}{lll}K_{B N} & & \\ & K_{B T} & \\ & & K_{B T}\end{array}\right]$. When the normal course of the boundary surface was parallel to the $y$-axis, it was $\left[\begin{array}{lll}K_{B T} & & \\ & K_{B N} & \\ & & K_{B T}\end{array}\right]$. When the normal course of the 


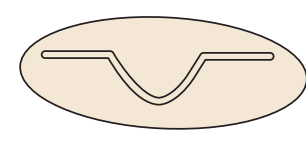

$\mathrm{NR}=1$

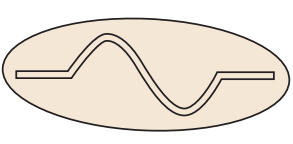

$\mathrm{NR}=2$

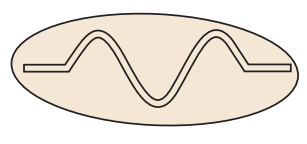

$\mathrm{NR}=3$

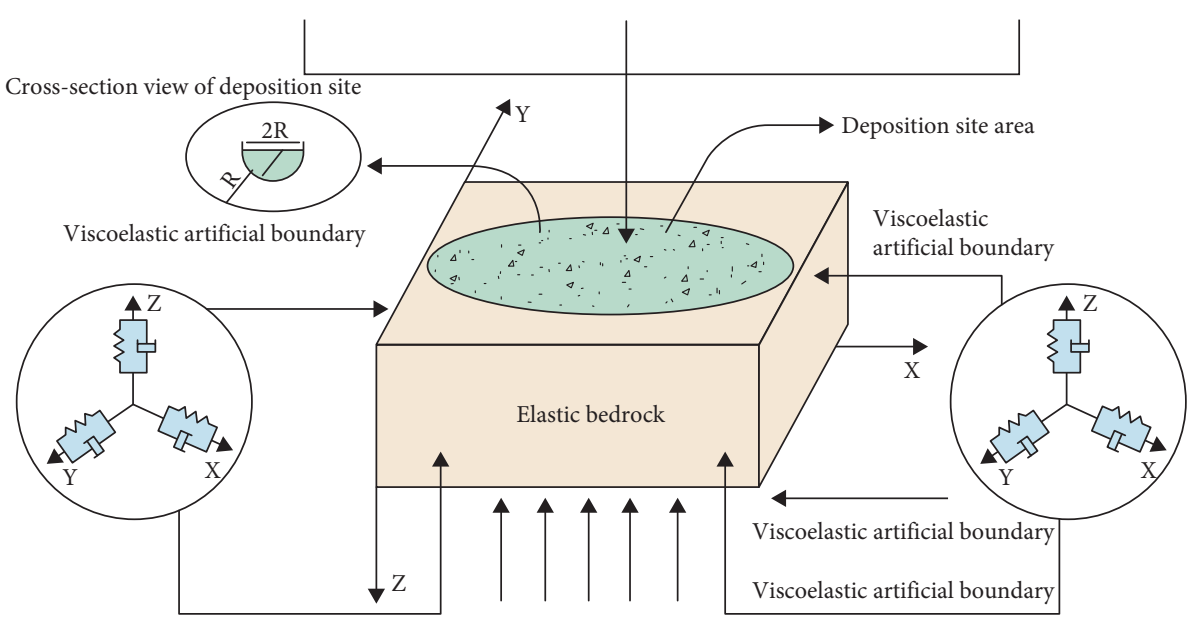

Viscoelastic artificial boundary SV wave bottom surface perpendicular incidence

FIgURE 3: Model diagram (NR indicates the number of meanders in a bent sedimentary valley).

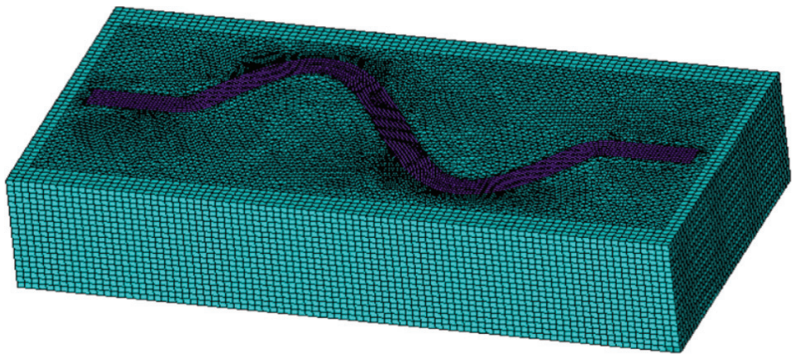

FIGURE 4: Discrete finite element model $(\mathrm{NR}=2)$.

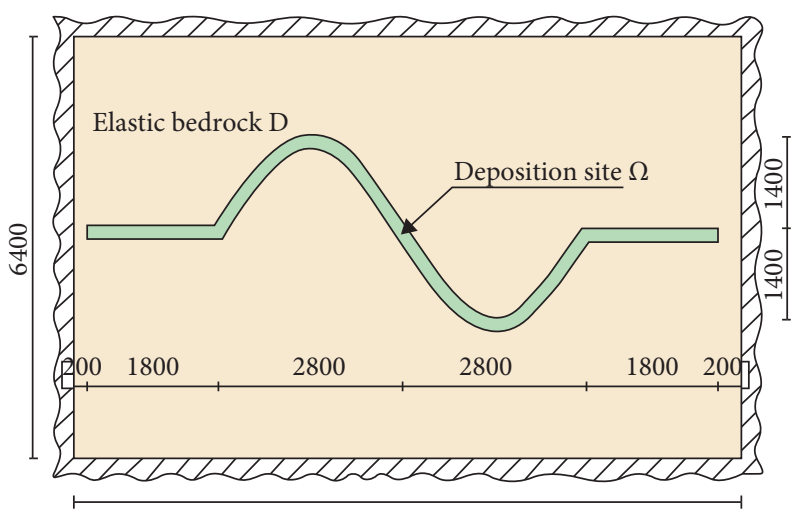

Figure 5: The $X Y$ plane of two meandering river valleys.

boundary surface was parallel to the $z$-axis, it was $\left[\begin{array}{ccc}K_{B T} & & \\ & K_{B T} & \\ & & K_{B N}\end{array}\right]$. We could obtain $C_{b}$ in the same way.

In the actual calculation, the generally known surface acceleration timescales were inverted to obtain the acceleration incident waves at the ground surface of the finite ground base for the calculation of the interception and then integrated. The corresponding velocity and displacement incident waves could be obtained, and then, the velocity and displacement of the entire free field could be obtained according to the one-dimensional wave theory. 
The method for converting the ground vibration input at the boundary node into the equivalent node load input was implemented by taking the analytic stress timings corresponding to the incident displacement timings of the bottom boundary and the free field timings of the side boundary as the boundary load. A further derivation of the ground-vibration input equation was performed to convert the stress of the desired free field into the displacement and velocity of the solved free field.

Because of the length, only the equivalent nodal force formula of the bottom boundary is given below when $\mathrm{P}$ wave, SV wave, and SH wave are vertically incident.

The equivalent nodal force of the bottom boundary when $\mathrm{P}$ wave is incident vertically can be written as follows:

$$
\left\{\begin{array}{l}
F_{x}^{-z}=0 \\
F_{y}^{-z}=\left\{K_{B T}\left[v_{0}(t)\right]+v_{0}\left(t-\frac{2 H}{c_{s}}\right)+C_{B T}\left[\dot{v}_{0}(t)+\dot{v}_{0}\left(t-\frac{2 H}{c_{s}}\right)\right]+\rho c_{s}\left[\dot{v}_{0}(t)+\dot{v}_{0}\left(t-\frac{2 H}{c_{s}}\right)\right]\right\} A_{b} \\
F_{z}^{-z}=0
\end{array}\right.
$$

The equivalent nodal force of the lower bound when the SV wave is incident vertically can be written as follows:

$$
\left\{\begin{array}{l}
F_{x}^{-z}=\left\{K_{B T}\left[u_{0}(t)\right]+u_{0}\left(t-\frac{2 H}{c_{s}}\right)+C_{B T}\left[\dot{u}_{0}(t)+\dot{u}_{0}\left(t-\frac{2 H}{c_{s}}\right)\right]+\rho c_{s}\left[\dot{u}_{0}(t)-\dot{u}_{0}\left(t-\frac{2 H}{c_{s}}\right)\right]\right\} \cdot A_{b} \\
F_{y}^{-z}=0 \\
F_{z}^{-z}=0
\end{array}\right.
$$

The equivalent nodal force of the lower bound when the $\mathrm{SH}$ wave is incident vertically can be reported as follows:

$$
\left\{\begin{array}{l}
F_{x}^{-z}=0 \\
F_{y}^{-z}=\left\{K_{B T}\left[v_{0}(t)\right]+v_{0}\left(t-\frac{2 H}{c_{s}}\right)+C_{B T}\left[\dot{v}_{0}(t)+\dot{v}_{0}\left(t-\frac{2 H}{c_{s}}\right)\right]+\rho c_{s}\left[\dot{v}_{0}(t)+\dot{v}_{0}\left(t-\frac{2 H}{c_{s}}\right)\right]\right\} A_{b} \\
F_{z}^{-z}=0
\end{array}\right.
$$

The superscript of the equivalent load indicates the normal direction of the interface where the node was cut off, and the subscript indicates the direction of the equivalent load. The formulas for the equivalent node forces of the other four surfaces were similar.

According to the fast Fourier algorithm FFT (fast Fourier transform), the corresponding ground motion input in the time domain needed to be converted into the fast Fourier transform and into the ground motion input in the frequency domain. The formula of the incident wave and the reflected wave in the frequency domain was $e^{i \omega t \pm i k z}$. Among the variables, $\omega$ is the angular frequency of the incident wave, $k$ is the wave number of $\mathrm{P}, \mathrm{SV}$, and $\mathrm{SH}$, and $z$ is the depth of this node. The equivalent load on the viscoelastic bottom surface boundary in the frequency domain could be obtained with the Fourier transform. 
The equivalent nodal force of the bottom edge in the frequency domain when the $\mathrm{P}$ wave is incident vertically can be written as follows:

$$
\left\{\begin{array}{l}
F_{x}^{-z}=0 \\
F_{y}^{-z}=0 \\
F_{z}^{-z}=\left[K_{B T} \cdot 2 \cos (k z)+\rho c_{s} \cdot(-1) \cdot 2 \omega \sin (k z)+i \cdot C_{B T} \cdot 2 \omega \cos (k z)\right] \cdot A_{b}
\end{array}\right.
$$

The equivalent nodal force of the lower edge in the frequency domain when the SV wave is incident vertically can be written as follows:

$$
\left\{\begin{array}{l}
F_{x}^{-z}=\left[K_{B T} \cdot 2 \cos (k z)+\rho c_{s} \cdot(-1) \cdot 2 \omega \sin (k z)+i \cdot C_{B T} \cdot 2 \omega \cos (k z)\right] \cdot A_{b} \\
F_{x}^{-z}=0 \\
F_{x}^{-z}=0
\end{array}\right.
$$

The equivalent nodal force of the lower edge in the frequency domain when the HS wave is incident vertically can be written as follows:

$$
\left\{\begin{array}{l}
F_{x}^{-z}=\left[K_{B T} \cdot 2 \cos (k z)+\rho c_{s} \cdot(-1) \cdot 2 \omega \sin (k z)+i \cdot C_{B T} \cdot 2 \omega \cos (k z)\right] \cdot A_{b} \\
F_{z}^{-z}=0 \\
F_{z}^{-z}=\rho c_{s} \cdot(-1) \cdot 2 \omega \sin (k z) \cdot A_{b} .
\end{array}\right.
$$

\section{Accuracy Verification}

Owing to the lack of a completely accurate analytic solution for the scattering of elastic waves by a $3 \mathrm{D}$ alluvial basin, the accuracy verification was performed by comparing the results with the available solutions by accurate numerical methods.

To verify the numerical precision of applying the harmonic response analysis to solve the seismic response of sedimentary basins using viscoelastic boundaries, Figures 7-9 are created, showing the surface displacement amplitudes around a hemispherical basin with a radius of $200 \mathrm{~m}$ in a homogeneous half-space compared with the $3 \mathrm{D}$ results of Mossessian [39, 69]. The parameters for the model were as follows: basin radius $R=200 \mathrm{~m}$, shear wave velocity in the basin $v_{s 1}=500 \mathrm{~m} / \mathrm{s}$, compression wave velocity $v_{P 1}=1000 \mathrm{~m} / \mathrm{s}$, density $\rho_{1}=1400 \mathrm{~kg} / \mathrm{m}^{3}$, shear wave velocity outside the basin $v_{s 2}=500 \mathrm{~m} / \mathrm{s}$, compression wave velocity $v_{P 2}=500 \mathrm{~m} / \mathrm{s}$, density $\rho_{2}=2000 \mathrm{~kg} / \mathrm{m}^{3}$, both inside and outside Poisson's ratio $\mu=0.3$, and dimensionless frequency $\eta=0.5$ and $\eta=0.75$.

Figures 7-9 show that the results of the present study agreed well when solving the seismic response of sedimentary basins. At the same time, the results in Figure 9 also show that the existence of the sedimentary basin had a significant effect on the amplification of seismic waves.

\section{Numerical Results and Discussions}

4.1. The Influence of the Excitation Frequency. Figures 9-26 show the overlooking cloud diagram of the surface displacement amplitude of the site of a three-dimensional meandering valley when $\mathrm{P}, \mathrm{SV}$, and $\mathrm{SH}$ waves of different frequencies incident uniformly meandering sedimentary valleys. Figures $10,11,16,21$, and 22, are the surface displacement amplitude of the meandering valley under the incident $\mathrm{P}$ wave, Figures 12, 13, 17, 18, 23, and 24 are the surface displacement amplitude of the meandering valley under the incident SV wave, and Figures 14, 15, 19, 20, 25, and 26 are the surface displacement amplitude of the meandering valley under the incident $\mathrm{SH}$ wave. As can be seen from the figures, no matter $\mathrm{P}, \mathrm{SV}$, or $\mathrm{SH}$ waves, the spatial displacement distribution presents a strong center symmetry, indicating that the amplitude distribution of surface displacement of low frequencies is more simple. When the incident wave frequency increases in high frequency, the surface displacement amplitude presents a more complex form and the surface spatial displacement amplitude distribution of the meandering river valley becomes complex. In addition, with the increase of incident frequency at low frequency, the amplitude of surface displacement increases significantly; with the increase of incident wave frequency at high frequency, the surface displacement 


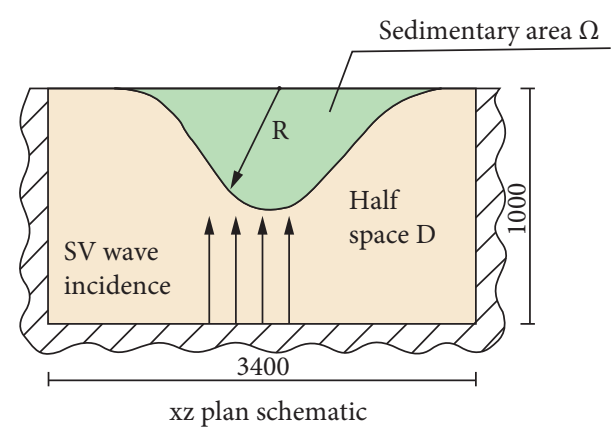

FIGURE 6: The YZ plane of two meandering river valleys.

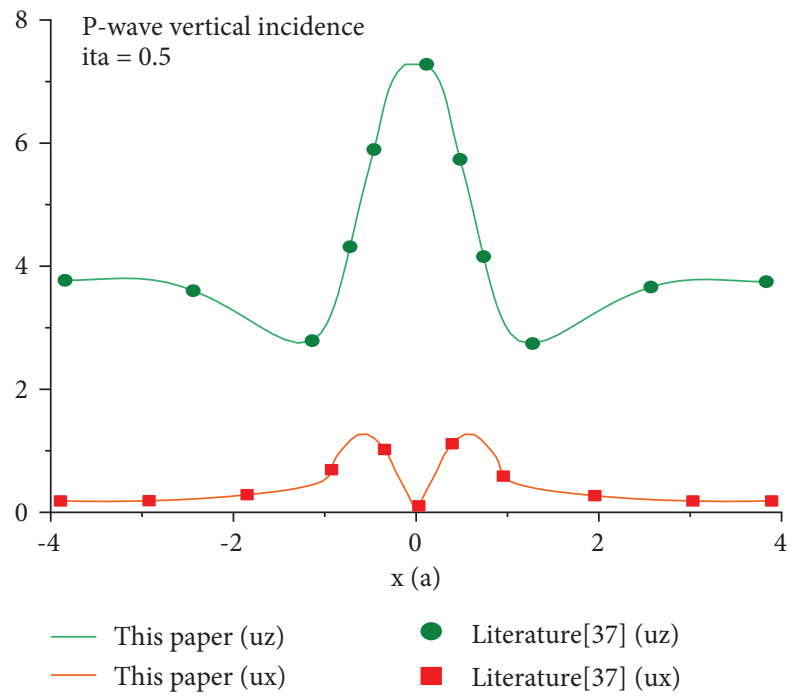

Figure 7: $P$-wave vertical incidence surface displacement amplitude $(Y=0$ and $Z=0)$.

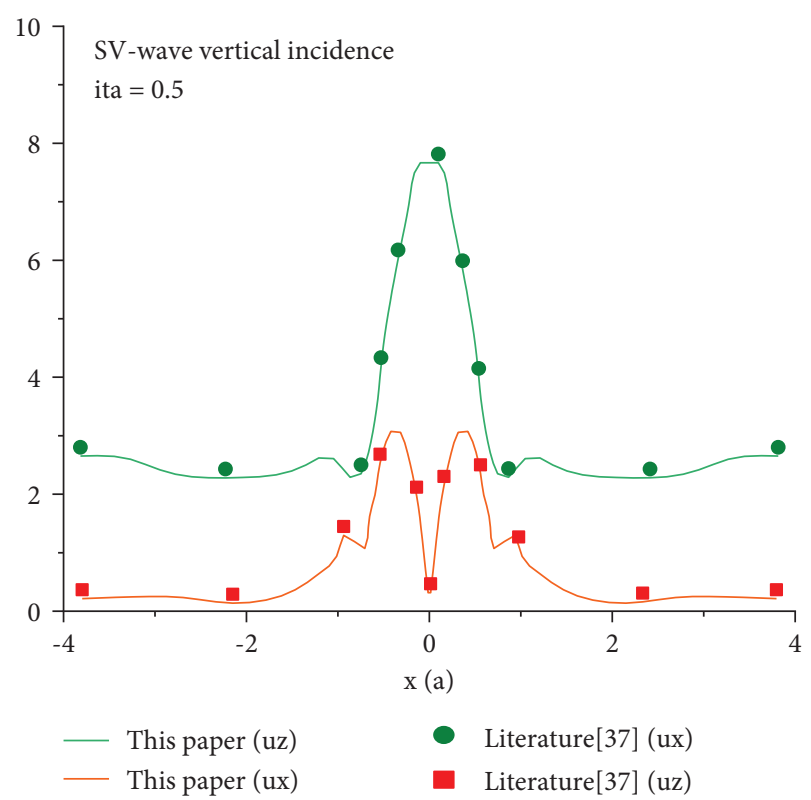

FIGURE 8: SV-wave vertical incidence surface displacement amplitude $(Y=0$ and $Z=0)$. appears multipoint focusing alternating amplification and significant attenuation effect.

Figures 10 and 11 show that when the P-wave frequency $f=1.5 \mathrm{~Hz}, 2.0 \mathrm{~Hz}$, the main direction of displacement $U x$ presents the overall displacement amplification; at the same time, the half-space free field displacement near the meandering valley also has an amplification effect, and the surface displacement in the enlarged area shows a focusing effect along the horizontal center of the valley. This is because the vibration direction of the $\mathrm{P}$ wave is perpendicular to the axis of sedimentary valley; the sinuous sedimentary valley vibrates vertically as a whole as the soft soil valley. The deposition meandering valley shows centers focusing amplification, and the amplification effect of the valley cross section decreases along both sides. Taking the displacement $U x$ in the main direction $f=2.0 \mathrm{~Hz}$ as an example, the center displacement peak of the meandering valley is 3.9 and the edge displacement peak is 2.8 , which is $39.3 \%$ higher than that of the edge center focusing effect of the meandering valley. Also, with the increase of incident wave frequency, the displacement peak in the main direction increases significantly and the displacement peak of $f=2.0 \mathrm{~Hz}$ increases $77.3 \%$ compared with $f=1.5 \mathrm{~Hz}$. In particular, it can be seen from the figures that the displacement peaks of $U x$ and $U y$ in the secondary direction are concentrated near the edge of the meandering valley, showing "an edge effect." Similarly, with the increase of incident wave frequency, the displacement in the secondary direction also increases to a certain extent.

As shown in Figures 12 and 13, when the low-frequency SV wave is incident, the deposition site is a soft soil layer and the whole site of the meandering valley has a certain degree of amplification effect. Different from the incident of $\mathrm{P}$ wave, when $\mathrm{NR}=2$, the displacement amplification effect of the meandering partially and the linear part of the site of the meandering deposition valley is different. The displacement $U x$ in the main direction shows that the displacement amplification is obvious within a certain range of $x=3400 \mathrm{~m}$ and $x=4800 \mathrm{~m}$ (meandering corner). This is because when the SV wave vibrates along the $x$-direction, the included angle between the valley axis and the vibration direction is small, while the sight axis in other meandering sections is basically vertical to the vibration direction. Similar to the general deposition site, the displacement amplification area shows the center focusing effect, and at low frequency, the displacement amplitude increases significantly with the increase of incident wave frequency. For example, the surface displacement amplitude is 5.0 when $f=1.5 \mathrm{~Hz}$, which increases by about $85.2 \%$ compared with the peak value of the surface displacement when $f=1.0 \mathrm{~Hz}$. The amplifying regions of $U y$ and $U z$ displacement in the secondary direction are opposite to those in the main direction. The displacement $U y$ shows central focusing, the displacement $U z$ shows an edge effect, and the increase of incident wave frequency will obviously increase the displacement peak in the secondary direction; for example, when $f=1.5 \mathrm{~Hz}$, the displacement $U y$ is amplified 5 times relative to the displacement peak value of $1.0 \mathrm{~Hz}$.

Figures 14 and 15 show that the $\mathrm{SH}$ wave incident at low frequency $(f=1.0 \mathrm{~Hz}, 1.5 \mathrm{~Hz}$, and $1.8 \mathrm{~Hz})$ is similar to the $\mathrm{SV}$ wave incident. The main direction displacement $U y$ has a 


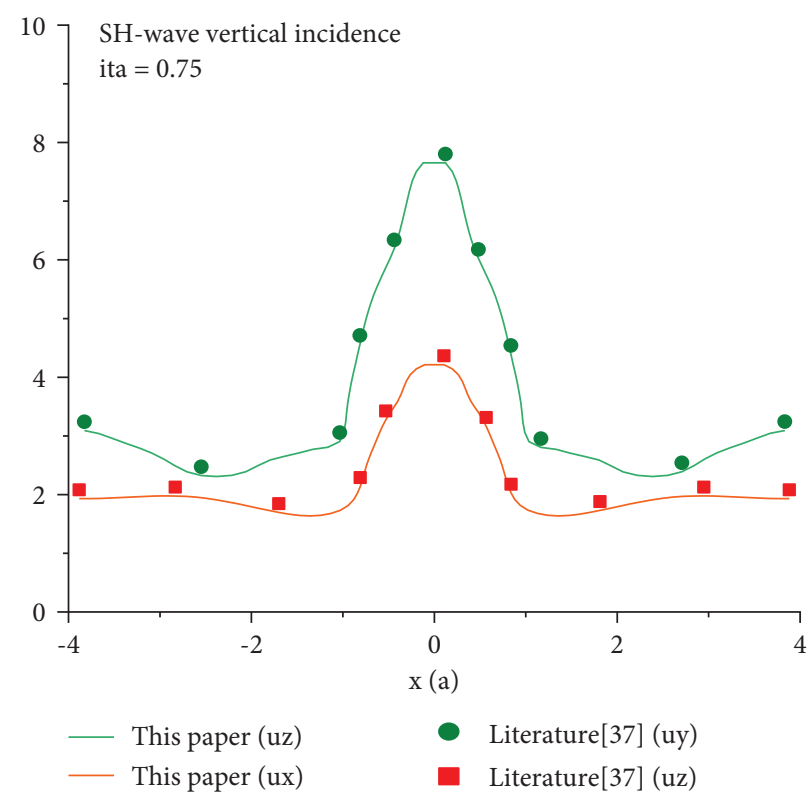

Figure 9: Surface displacement amplitude by SH-wave vertical incidence $(Y=0$ and $Z=0)$.

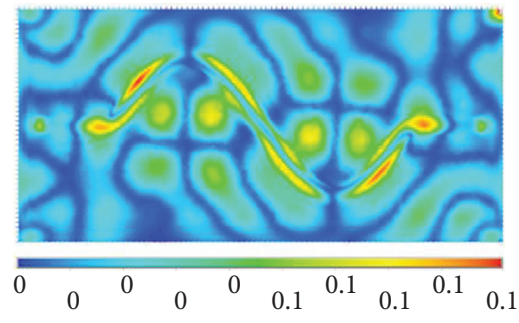

(a)

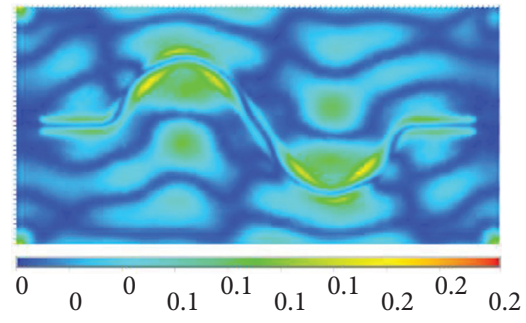

(b)

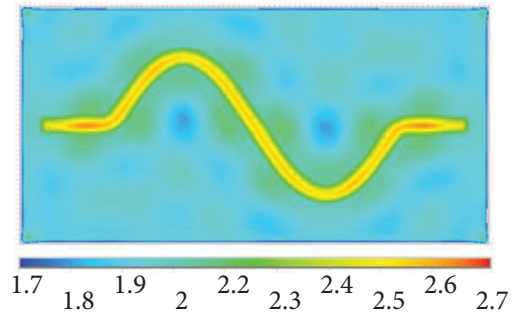

(c)

Figure 10: P wave incident $\left(f=1.5 \mathrm{~Hz}, H=100 \mathrm{~m}, C_{\mathrm{s}}=500 \mathrm{~m} / \mathrm{s}\right.$, and $\left.\mathrm{NR}=2\right)$. Top view displacement cloud view (a) $u_{x}$, (b) $u_{y}$, and (c) $u_{z}$.

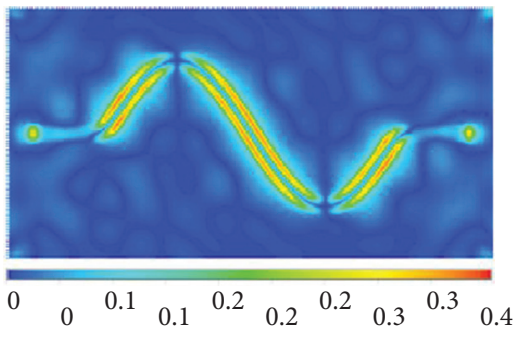

(a)

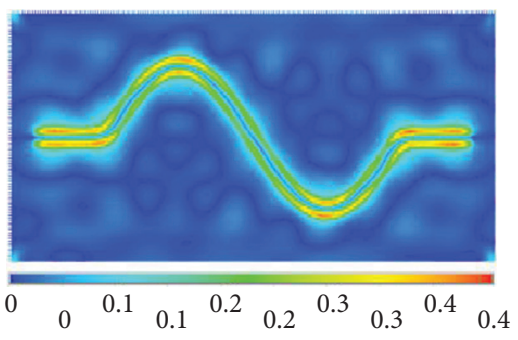

(b)

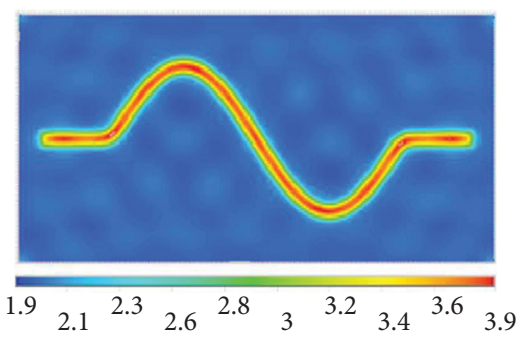

(c)

Figure 11: $P$ wave incident $\left(f=2.9 \mathrm{~Hz}, H=100 \mathrm{~m}, C_{\mathrm{s}}=500 \mathrm{~m} / \mathrm{s}\right.$, and NR=2). Top view displacement cloud view (a) $u_{x}$, (b) $u_{y}$, and (c) $u_{z}$.

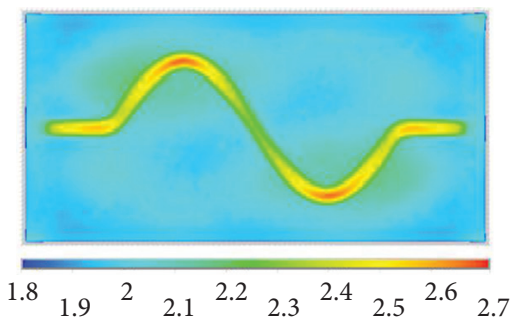

(a)

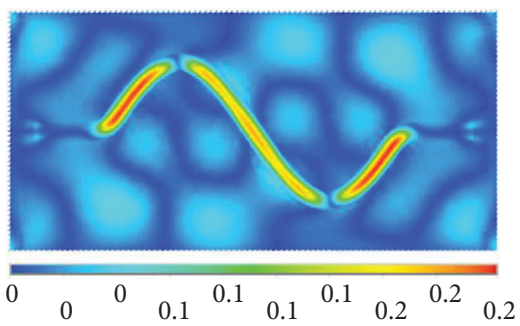

(b)

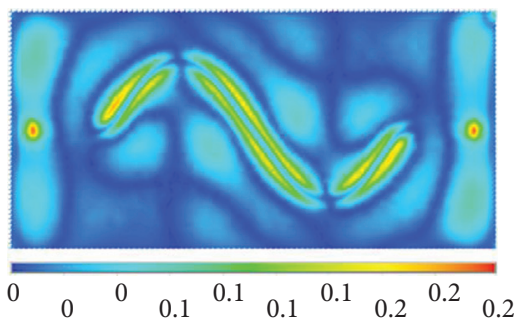

(c)

Figure 12: SV wave incident $\left(f=1.0 \mathrm{~Hz}, H=100 \mathrm{~m}, C_{\mathrm{s}}=500 \mathrm{~m} / \mathrm{s}\right.$, and $\left.\mathrm{NR}=2\right)$. Top view displacement cloud view (a) $u_{x}$, (b) $u_{y}$, and (c) $u_{z}$. 


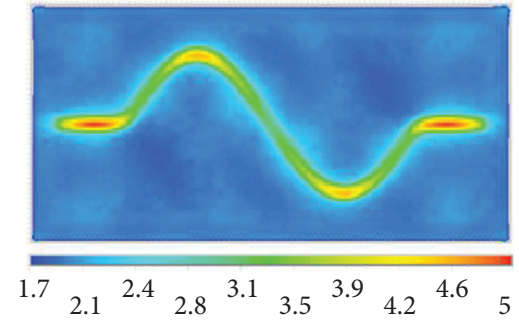

(a)

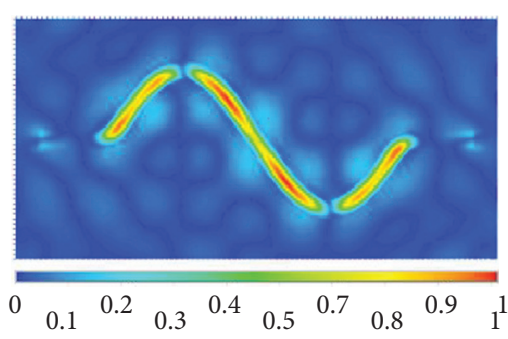

(b)

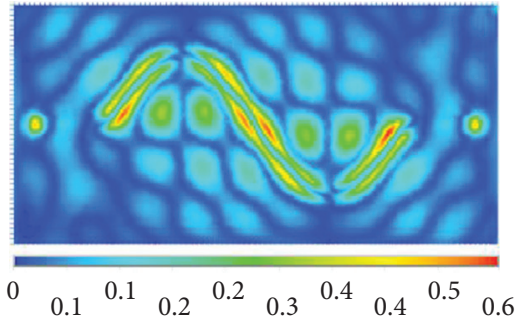

(c)

Figure 13: SV wave incident $\left(f=1.5 \mathrm{~Hz}, H=100 \mathrm{~m}, C_{\mathrm{s}}=500 \mathrm{~m} / \mathrm{s}\right.$, and $\left.\mathrm{NR}=2\right)$. Top view displacement cloud view (a) $u_{x}$, (b) $u_{y}$, and (c) $u_{z}$.

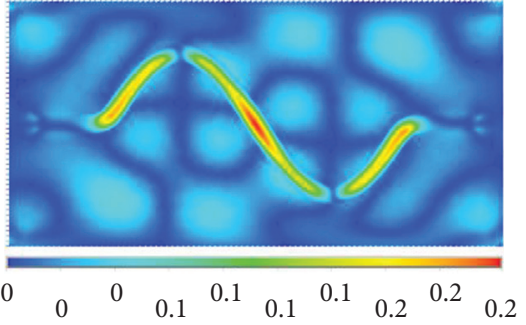

(a)

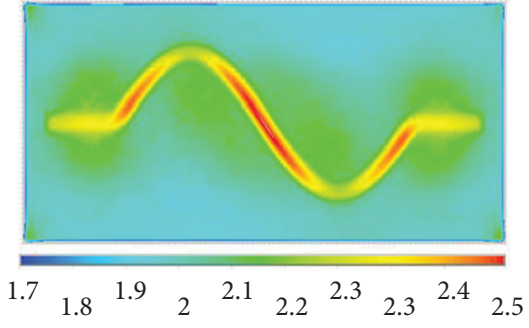

(b)

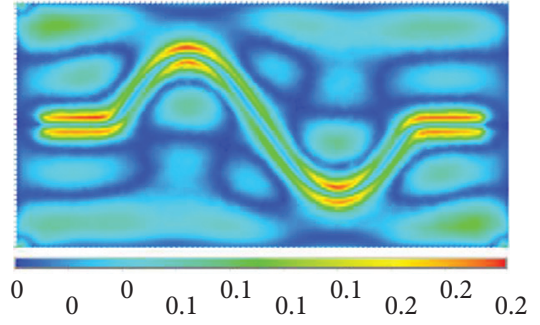

(c)

FiguRE 14: SH wave incident $\left(f=1.0 \mathrm{~Hz}, H=100 \mathrm{~m}, C_{\mathrm{s}}=500 \mathrm{~m} / \mathrm{s}\right.$, and $\left.\mathrm{NR}=2\right)$. Top view displacement cloud view (a) $u_{x}$, (b) $u_{y}$, and (c) $u_{z}$.

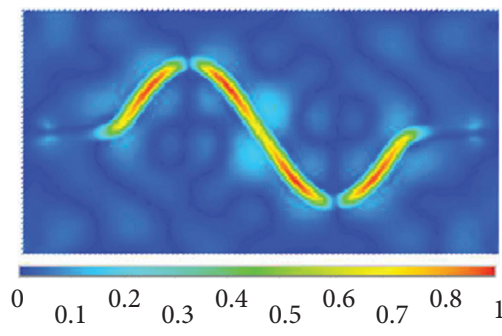

(a)

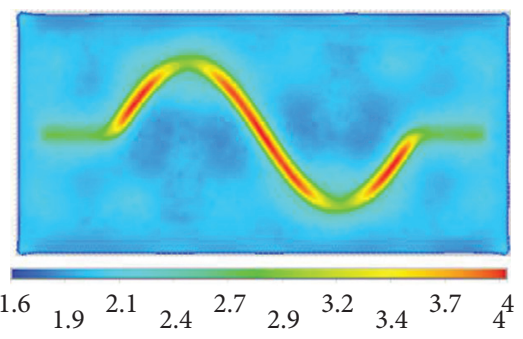

(b)

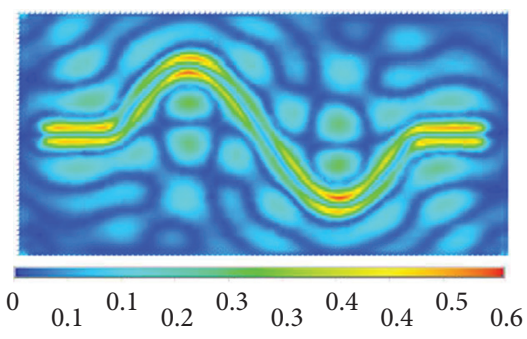

(c)

FIGURE 15: SH wave incident $\left(f=1.5 \mathrm{~Hz}, H=100 \mathrm{~m}, C_{\mathrm{s}}=500 \mathrm{~m} / \mathrm{s}\right.$, and $\left.\mathrm{NR}=2\right)$. Top view displacement cloud view (a) $u_{x}$, (b) $u_{y}$, and (c) $u_{z}$.

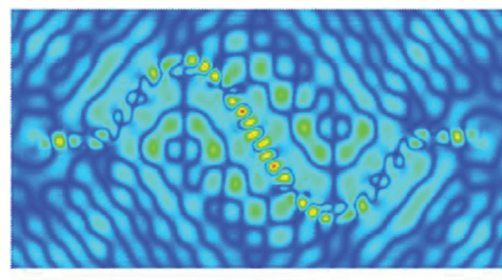

$\begin{array}{llllllllllll}0 & 0.2 & 0.4 & 0.6 & 0.9 & 1.1 & 1.3 & 1.5 & 1.7 & 2\end{array}$

(a)

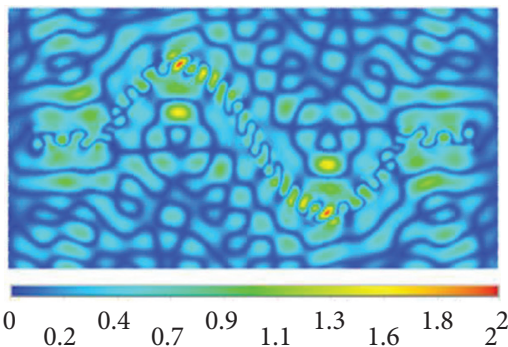

(b)

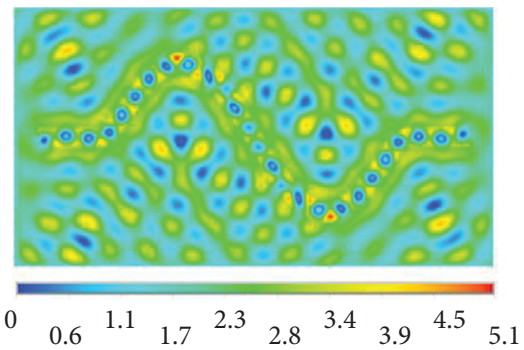

(c)

Figure 16: $P$ wave incident $\left(f=3.0 \mathrm{~Hz}, H=100 \mathrm{~m}, C_{\mathrm{s}}=500 \mathrm{~m} / \mathrm{s}\right.$, and $\left.\mathrm{NR}=2\right)$. Top view displacement cloud view (a) $u_{x}$, (b) $u_{y}$, and (c) $u_{z}$.

certain degree of amplification effect in the whole site of the meandering valley, and the amplification effect becomes more obvious in the meandering valley section (except the meandering corner). The reasons are as follows: the $\mathrm{SH}$ wave vibrates along the $y$-direction. The angle between the axis of the deposition meandering valley and the vibration direction is small, while the axes of other sites are basically vertical to the vibration direction. Therefore, the meandering valley section (excluding the meandering corners) intensifies the vibration of the site and the displacement amplitude is large. 


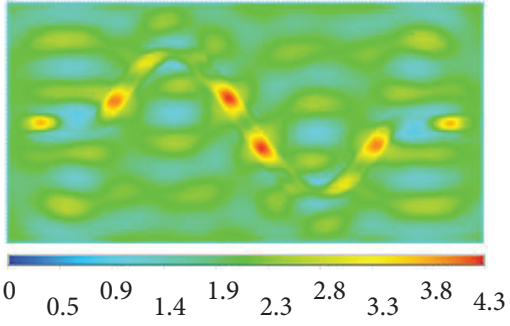

(a)

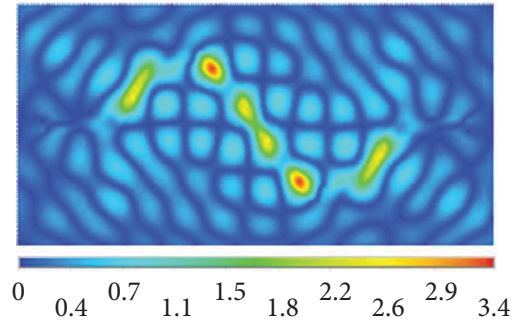

(b)

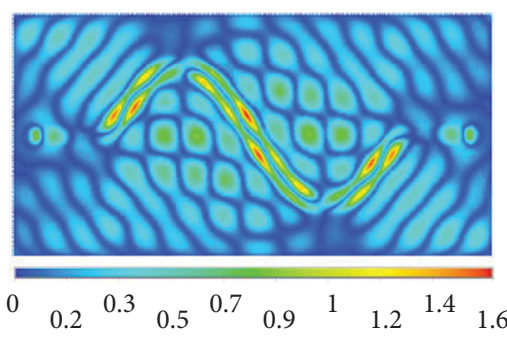

(c)

FIGURe 17: SV wave incident $\left(f=2.0 \mathrm{~Hz}, H=100 \mathrm{~m}, C_{\mathrm{s}}=500 \mathrm{~m} / \mathrm{s}\right.$, and NR=2). Top view displacement cloud view (a) $u_{x}$, (b) $u_{y}$, and (c) $u_{z}$.

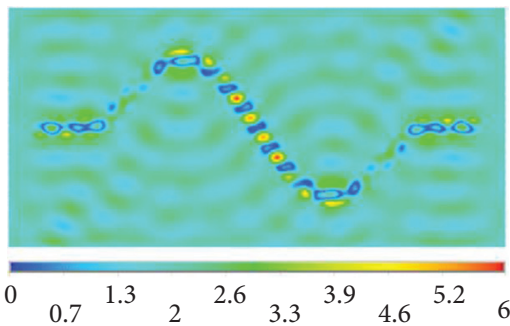

(a)

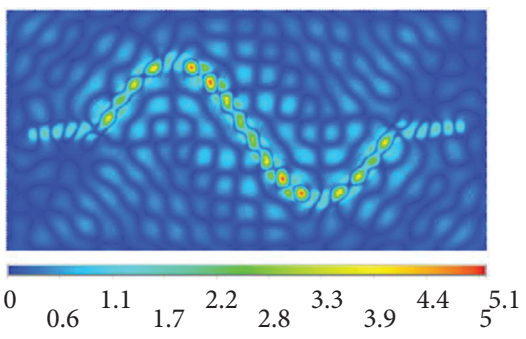

(b)

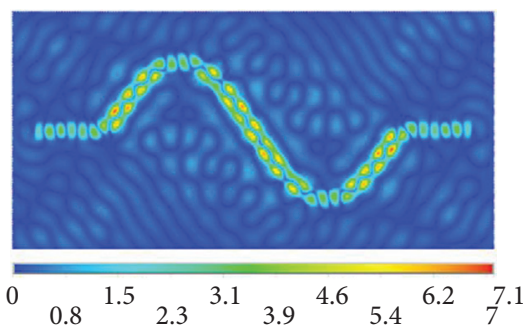

(c)

Figure 18: SV wave incident $\left(f=3.0 \mathrm{~Hz}, H=100 \mathrm{~m}, C_{\mathrm{s}}=500 \mathrm{~m} / \mathrm{s}\right.$, and $\left.\mathrm{NR}=2\right)$. Top view displacement cloud view (a) $u_{x}$, (b) $u_{y}$, and (c) $u_{z}$.

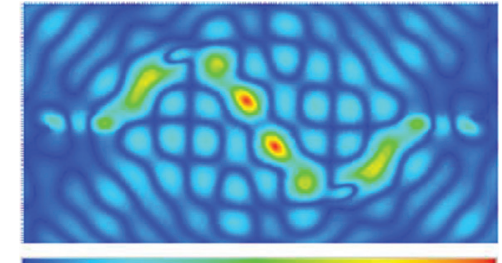

$\begin{array}{llllllllll}0 & 0.3 & 0.6 & 0.9 & 1.2 & 1.5 & 1.8 & 2.1 & 2.4 & 2.8\end{array}$

(a)

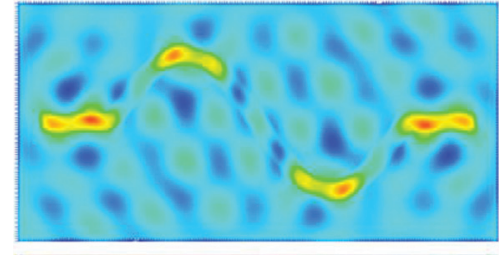

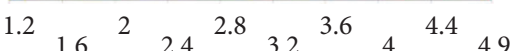

(b)

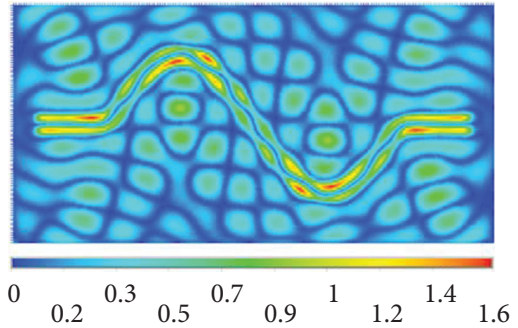

(c)

Figure 19: SH wave incident $\left(f=2.0 \mathrm{~Hz}, H=100 \mathrm{~m}, C_{\mathrm{s}}=500 \mathrm{~m} / \mathrm{s}\right.$, and $\left.\mathrm{NR}=2\right)$. Top view displacement cloud view (a) $u_{x}$, (b) $u_{y}$, and (c) $u_{z}$.

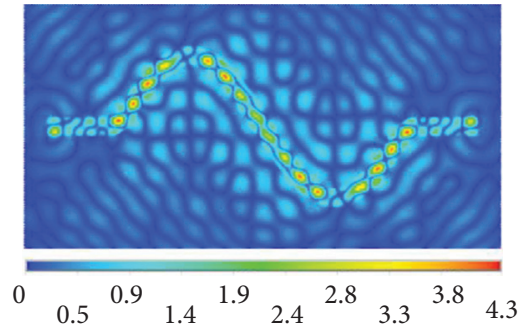

(a)

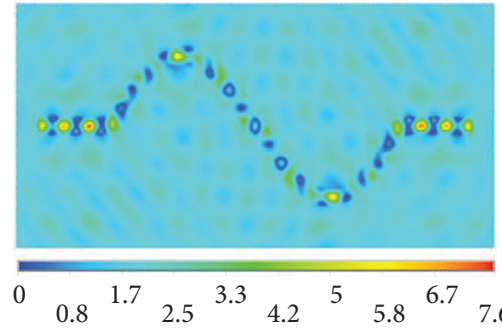

(b)

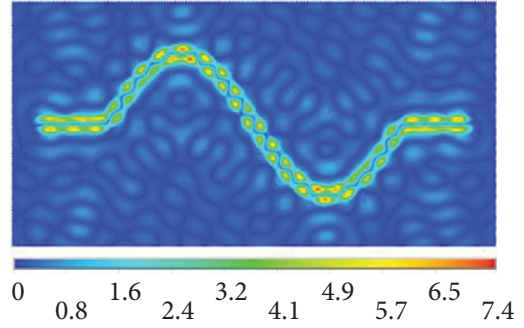

(c)

Figure 20: SH wave incident $\left(f=.3 .0 \mathrm{~Hz}, H=100 \mathrm{~m}, C_{\mathrm{s}}=500 \mathrm{~m} / \mathrm{s}\right.$, and NR=2). Top view displacement cloud view (a) $u_{x}$, (b) $u_{y}$, and (c) $u_{z}$.

Moreover, with the increase of incident wave frequency, the center focusing effect becomes more obvious and the amplitude of the displacement peak at $f=1.5 \mathrm{~Hz}$ is $60 \%$ higher than that at $f=1.0 \mathrm{~Hz}$. The secondary displacement $U x$ is centered on the sinuous segment. $U z$ presents an edge focusing, focusing on straight lines and winding corners. With the increase of incident wave frequency, the displacement peak in the secondary-direction increases exponentially. For example, the $U y$ displacement peak in the secondary direction $(f=1.5 \mathrm{~Hz})$ is 5 times that of $f=1.0 \mathrm{~Hz}$ 

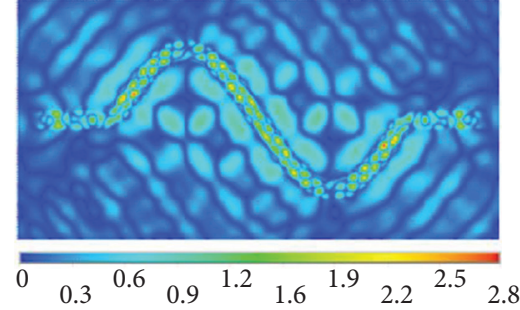

(a)

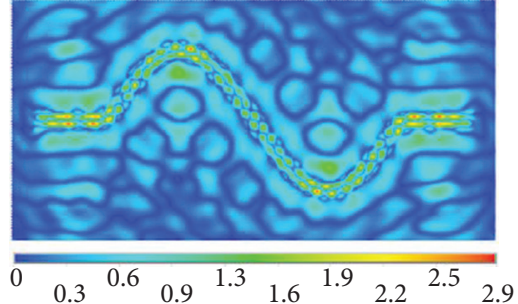

(b)

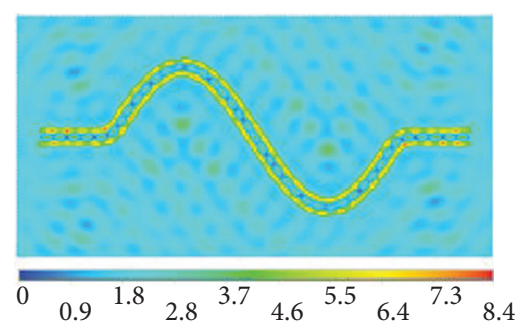

(c)

Figure 21: $P$ wave incident $\left(f=4.0 \mathrm{~Hz}, H=100 \mathrm{~m}, C_{\mathrm{s}}=500 \mathrm{~m} / \mathrm{s}\right.$, and $\left.\mathrm{NR}=2\right)$. Top view displacement cloud view (a) $u_{x}$, (b) $u_{y}$, and (c) $u_{z}$.
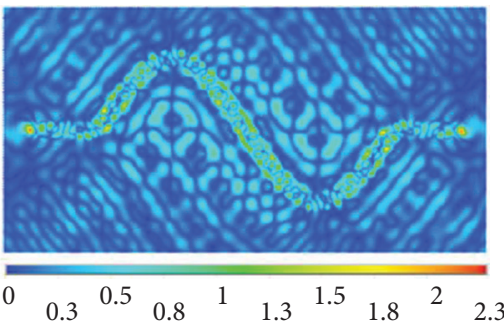

(a)

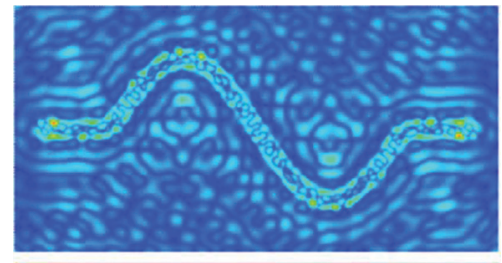

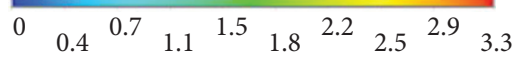

(b)

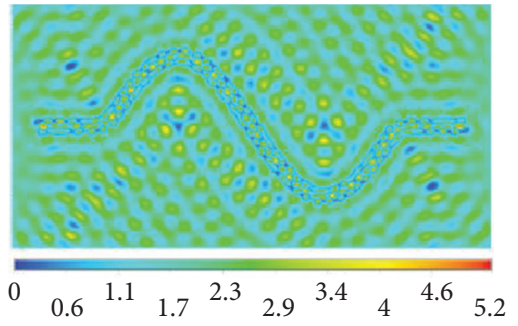

(c)

Figure 22: $P$ wave incident $\left(f=5.0 \mathrm{~Hz}, H=100 \mathrm{~m}, C_{s}=500 \mathrm{~m} / \mathrm{s}, \mathrm{NR}=2\right)$. Top view displacement cloud view (a) $u_{x}$, (b) $u_{y}$, and (c) $u_{z}$.
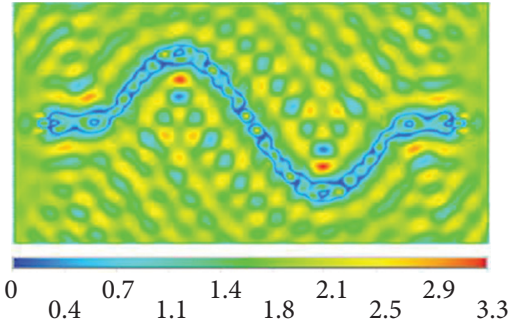

(a)
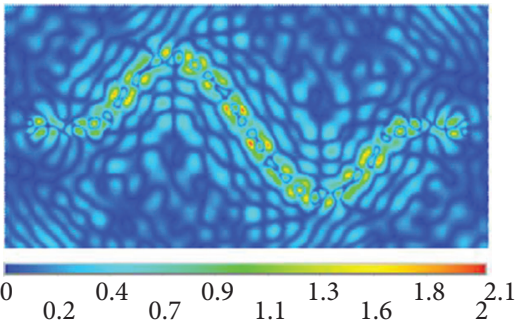

(b)

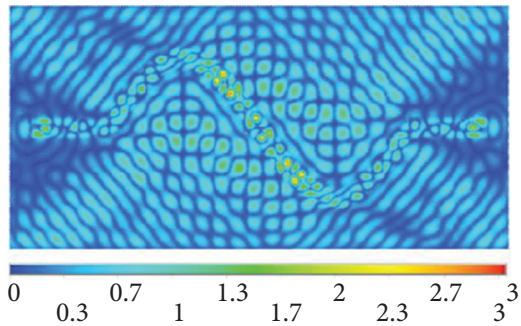

(c)

Figure 23: SV wave incident $\left(f=4.0 \mathrm{~Hz}, H=100 \mathrm{~m}, C_{s}=500 \mathrm{~m} / \mathrm{s}, \mathrm{NR}=2\right)$. Top view displacement cloud view (a) $u_{x}$, (b) $u_{y}$, and (c) $u_{z}$.

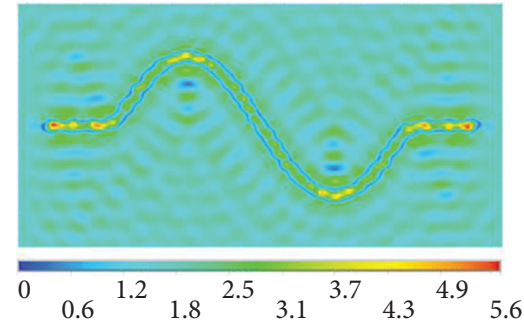

(a)

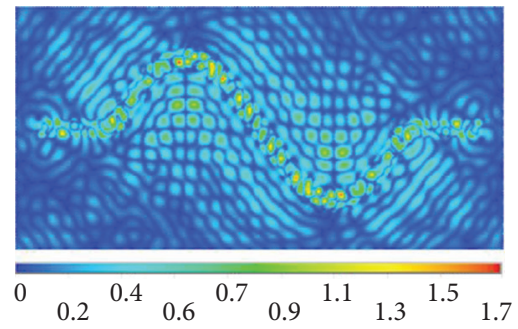

(b)

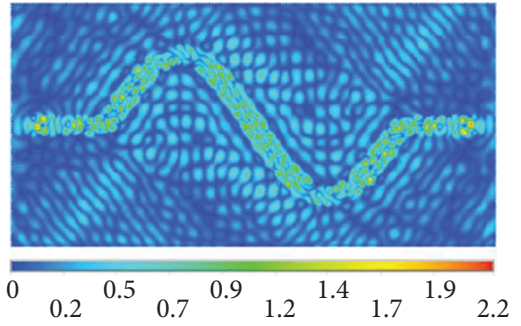

(c)

FIGURe 24: SV wave incident $\left(f=5.0 \mathrm{~Hz}, H=100 \mathrm{~m}, C_{\mathrm{s}}=500 \mathrm{~m} / \mathrm{s}\right.$, and NR=2). Top view displacement cloud view (a) $u_{x}$, (b) $u_{y}$, and (c) $u_{z}$.

and the amplitude of $U z$ displacement in the case of $f=1.5 \mathrm{~Hz}$ is 3 times that of $f=1.0 \mathrm{~Hz}$.

It is worth noting that, as an asymmetric site, the site of meandering valley has multiorder and multidirection natural vibration frequency. When the incident wave frequency reaches the natural vibration frequency in the corresponding direction, the surface displacement in the corresponding direction will show a more complex form and the displacement amplitude will also increase significantly due to the resonance effect.

As shown in Figure 16, when the $\mathrm{P}$ wave is incident and a higher frequency is incident $(f=3.0 \mathrm{~Hz}), f=3.0 \mathrm{~Hz}$ is close to 


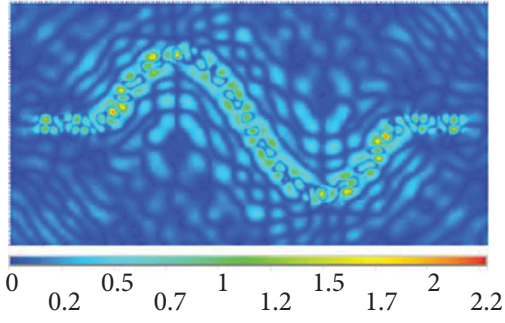

(a)

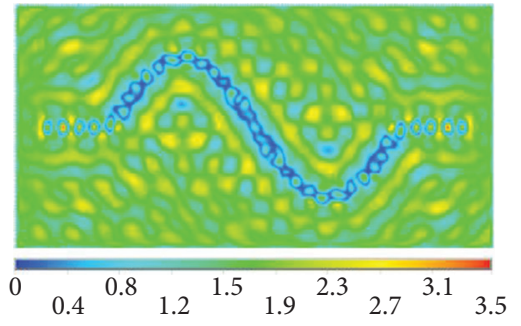

(b)

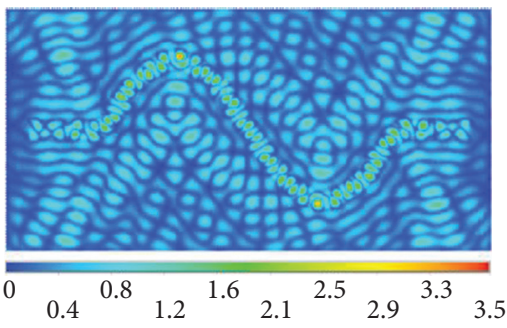

(c)

FiguRE 25: SH wave incident $\left(f=4.0 \mathrm{~Hz}, H=100 \mathrm{~m}, C_{\mathrm{s}}=500 \mathrm{~m} / \mathrm{s}\right.$, and $\left.\mathrm{NR}=2\right)$. Top view displacement cloud view (a) $u_{x}$, (b) $u_{y}$, and (c) $u_{z}$.

a certain natural vibration frequency of its vibration direction. The displacement amplitude distribution of the meandering valley is inconsistent with other forms. Because of the resonance effect, the maximum displacement peak value of the meandering valley is as high as 5.1 , which is 2.55 times larger than the half-space field. The amplification effect of $U y$ and $U z$ in the secondary $y$-direction is also obvious.

As shown in Figure 17, when an SV wave is incident $(f=2.0 \mathrm{~Hz})$, the incident frequency reaches the natural frequency in the $x$-direction of the valley, which is different from the incident frequency of other frequencies. On the contrary, the displacement of the sinuous valley section is obvious, with an amplitude of about 4.1. Meanwhile, it also intensifies the surface displacement amplitude of $U y$ in the secondary direction, with an amplitude of about 3.4. As shown in Figure 18, $f=3.0 \mathrm{~Hz}$ belongs to the natural vibration frequency in the $y$-direction of the meandering river valley and the displacement peak $U y$ in the $y$-direction of the surface is the largest, which is as high as about 5.1, and shows the multipoint center focusing effect.

As shown in Figure 19, when an SH wave is incident $(f=2.0 \mathrm{~Hz})$, the surface displacement amplitude presents different manifestations. The displacement amplification effect is obvious in the straight segment and winding corner, and the displacement amplitude in the main direction is 4.9. As shown in Figure 20, the $U y$ displacement peak in the main direction $(f=3.0 \mathrm{~Hz})$ is as high as 7.6 , which is 3.8 times larger than the displacement peak at the free site. It should be noted that the resonance effect also causes a large amplification effect of the secondary displacement. For example, when $f=3.0 \mathrm{~Hz}$ is incident, the secondary displacement $U x$ is as high as 4.3 and the $U z$ displacement peak is as high as 7.4.

Therefore, it can be fully demonstrated that the resonance effect will significantly affect the peak value and manifestation of surface displacement. When a high frequency of wave is incident, the spatial distribution of displacement amplitude of the meandering river valley becomes more complex, mainly showing the alternating occurrence of multipoint focusing. With the increase of incident frequency, the amplification and weakening of multipoint focusing become more obvious. Because of the existence of the site of the meandering river valley, the waveform is transformed and superimposed by the sedimentary transmission, body, and the surface displacement peak is amplified or weakened by multipoint focusing on the semispace site near the meandering river valley.
As shown in Figures 21 and 22, when $\mathrm{P}$ wave is incident vertically, for example, $f=4.0 \mathrm{~Hz}$ and $f=5.0 \mathrm{~Hz}$, multipoint focusing on the half-space field weakens the surface displacement amplitude and the multipoint range displacement of the site weakens to zero effect. The displacement $U x$ in the main direction of the meandering river valley shows the coexistence of multipoint center focusing and multipoint edge effect. $f=4.0 \mathrm{~Hz}$ shows the displacement amplification of the edge effect and the displacement weakening of the center focusing effect. $f=5.0 \mathrm{~Hz}$ is opposite to $f=4.0 \mathrm{~Hz}$, where edge effect weakens the displacement of the river valley and center focusing amplifies the displacement. The subdirection displacement $U y$ presents multipoint edge focus on the whole, while the $U x$ sinuous segment presents edge focus and the straight segment presents multipoint center focus.

As shown in Figures 23 and 24, when the SV wave is vertically incident and the incident frequency $f=4.0 \mathrm{~Hz}$, the deposition site acts as the transmission body of the incident wave and reflected wave, and the waveform has complex reflection and diffraction effects on both sides of the circular arc, resulting in a strong center focusing effect in a certain area at the center of the circular arc in the half-space field. As a result, the displacement peak of the half-space field in this region is greatly amplified or decreased. When $f=4.0 \mathrm{~Hz}$ is incident, the half-space free field has a bit peak amplification effect near the winding river valley, which is about $65 \%$. When $f=5.0 \mathrm{~Hz}$ is incident, the displacement in this region has a weakening effect and the displacement amplitude decreases to about 0 . Different from when a low frequency of wave is incident, when a high frequency of wave is incident, the subdirection displacement of straight-line region of meandering river valley also appears multipoint center focusing phenomenon, $f=4.0 \mathrm{~Hz}$ subdirection $U z$ straight-line segment displacement peak reaches up to about 3.0, $f=5.0 \mathrm{~Hz}$, "boundary effect" occurs, and displacement amplitude is 5.6. This phenomenon reflects that the meandering valley terrain needs to pay attention to the secondary displacement peak at the same time to prevent the occurrence of excessive secondary displacement peak.

As shown in Figures 25 and 26, when the $\mathrm{SH}$ wave is incident at a vertical high frequency $(f=4.0,5.0 \mathrm{~Hz})$, the spatial distribution of displacement amplitude of meandering river valley presents the effect of multipoint focusing radiation and the spatial displacement becomes more complex. When $f=4.0 \mathrm{~Hz}$, the surface displacement of 
the meandering valley site presents a central focus and the surface displacement of the valley is greatly weakened. Because of the complex coherent effect of the waveform in the valley terrain, the turbulence around the valley is intense and the half-space free field displacement has multipoint focusing amplification. The surface displacement of the site with $f=5.0 \mathrm{~Hz}$ is opposite to that of the site with $f=4.0$, and the site with a meandering valley presents the center focusing amplification.

4.2. The Influence of Depth of the River Valley. Figures 27-38 show the vertical cloud images of surface displacement amplitudes of three-dimensional meandering valleys at different depths under the vertical incident of $\mathrm{P}$, $\mathrm{SV}$, and $\mathrm{SH}$ waves. In order to more fully reflect the impact of sinuous valley depth on the surface displacement amplitude of incident waves, the incident waves in the model are all incident at a lower frequency in the sedimentary valley when studying the impact of valley depth. For P-wave analysis, the frequency of incident wave was $f=2.0 \mathrm{~Hz}$, and for SV and SH wave analysis, $f=2.0 \mathrm{~Hz}$. (To explain the reason, the characteristic law of $\mathrm{P}$-wave $f=1.0 \mathrm{~Hz}$ was not obvious through the above incident frequency analysis.) Figures 27-30 are the amplitude of surface displacement under $\mathrm{P}$ wave incident, Figures 31-34 are the amplitude of surface displacement under SV wave incident, and Figures 35-38 are the amplitude of surface displacement under $\mathrm{SH}$ wave incident.

As can be seen from Figures 27-30, the spatial distribution of the displacement in the main direction is simple when the $\mathrm{P}$ wave is incident and the displacement in the low frequency is in vertical uniform vibration. The displacement of the valley presents a focal amplification. The amplification effect of the cross section of the valley is weakened along the center of the section, and the displacement in the main direction $U z$ increases with the increase of the depth of the valley. The maximum displacement amplitude of $H=150 \mathrm{~m}$ depth is $35.9 \%$ higher than that of $H=100 \mathrm{~m}$ depth. The secondary displacement increases slightly. In particular, when $H=175 \mathrm{~m}$, the surface displacement amplitude of the site presents different manifestations and the secondary displacement increases significantly. The reason for this phenomenon may be that when $f=1.5 \mathrm{~Hz}$, the incident wave frequency reaches the natural frequency of the site at this depth, the displacement is significantly amplified, and the spatial distribution law is significantly different.

As can be seen in Figures 31-34, when the SV wave is incident, the same low-frequency incident displacement spatial distribution is relatively simple. Figures 31-34 show that the main direction of the displacement peak $U x$ appeared in the winding line segment and winding valley corner, the peak appeared in the opposite direction from the main direction of displacement, and $U x$ and $U y$ expressed a central focus and offers to show the edge effect. With the increase of sinuous valley depth, the amplification effect of displacement in all directions tends to be obvious with the increase of deposition depth and the displacement peak basically increases exponentially. When $H=150 \mathrm{~m}$, the $U x$ displacement peak of the meandering valley is 1.47 times that of $125 \mathrm{~m}$ and that of the deposition valley is 1.48 times that of $H=150 \mathrm{~m}$. It is noted that, at $x=200 \mathrm{~m}$ and $x=9400 \mathrm{~m}$ (the junction of the valley and half-space), subdirection displacement $U z$ presents "boundary effect," and with the increase of depth, "boundary effect" becomes more and more obvious; for example, when $H=175 \mathrm{~m}$ depth, its boundary effect displacement peak is as high as about 1.0. It is suggested that future projects need to pay attention to this "boundary effect."

It can be seen from Figures 35-38, when the SH wave is incident, the displacement spatial distribution of low-frequency incident is relatively simple and the manifestation is basically the same as the low-frequency incident discussed above. However, with the increase of valley depth, the sedimentary valley acts as a wave transmission, body, and the deeper the valley depth is, the transformation, diffraction, and scattering of incident waveform are more sufficient. The amplitudes of the displacement in the three directions of the valley surface will increase, and the amplitudes of the displacement in the winding corner will increase obviously, especially the $U x$ amplitude. When $H=150 \mathrm{~m}, U y$ amplitude in the main direction increases by $37.5 \%$ compared with that in $H=125 \mathrm{~m}$, and $U y$ amplitude $H=175 \mathrm{~m}$ increases by $34.1 \%$ compared with that $H=125 \mathrm{~m}$. Compared with $H=125 \mathrm{~m}$, the $U x$ amplitude in the subdirection of $H=150 \mathrm{~m}$ increases by $100 \%$ and the $U x$ amplitude in the valley of $H=175 \mathrm{~m}$ increases by $80 \%$. The $U z$ amplitude in the main direction of the valley with $H=150 \mathrm{~m}$ increases by $75 \%$ compared with that of the valley with $H=125 \mathrm{~m}$, and the $U z$ amplitude in the valley with $H=175 \mathrm{~m}$ increases by $57 \%$ compared with that in the valley with $H=125 \mathrm{~m}$. It can be seen that the depth of the sedimentary valley can significantly increase the displacement amplitudes in the three directions of the sinuous valley, and the amplification effect of the topography on seismic waves should be fully considered for projects with large actual depth.

\subsection{The Influence of Depth of the Shear Wave Velocity of the} Sedimentary Layer. Shear wave velocity determines soil stiffness. To study the influence of soil stiffness on the surface displacement amplitude of different meandering sedimentary valleys, the surface displacement amplitude cloud maps of $C_{\mathrm{s}}=300 \mathrm{~m} / \mathrm{s}, C_{\mathrm{s}}=400 \mathrm{~m} / \mathrm{s}, C_{\mathrm{s}}=500 \mathrm{~m} / \mathrm{s}$, and $C_{\mathrm{s}}=600 \mathrm{~m} / \mathrm{s}$ under the action of different incident waves are given below. Similarly, in order to fully reflect the research law, the lowfrequency incident wave is used to incident the sedimentary valley.

For the incident of $\mathrm{P}$ wave, the amplitude of surface displacement varies with soil stiffness, as shown in Figures 39-42. It can be seen that when the soil stiffness is smaller, the amplitude of surface displacement in three directions of the winding river valley becomes larger, that is, the amplification effect of soft soil on ground motion is obvious. The change of wave velocity in the low soil layer has a significant effect on the main direction displacement $U z$, but has little effect on the secondary direction displacement basically. When the shear wave velocity of the soil layer is 


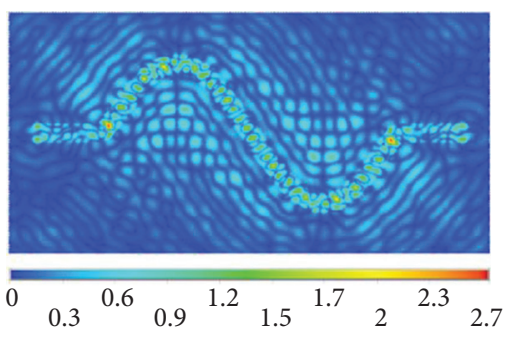

(a)

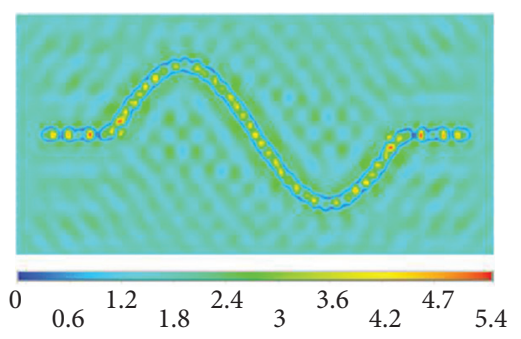

(b)

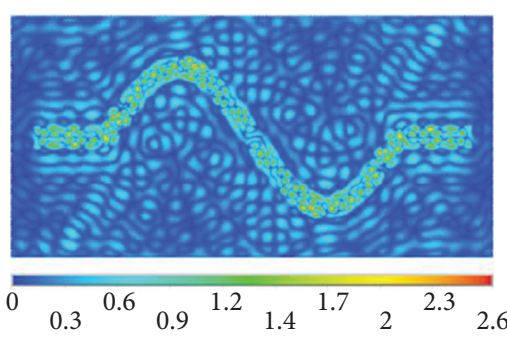

(c)

Figure 26: SH wave incident $\left(H=100 \mathrm{~m}, f=5.0 \mathrm{~Hz}, C_{\mathrm{s}}=500 \mathrm{~m} / \mathrm{s}\right.$, and NR=2). Top view displacement cloud view (a) $u_{x}$, (b) $u_{y}$, and (c) $u_{z}$.

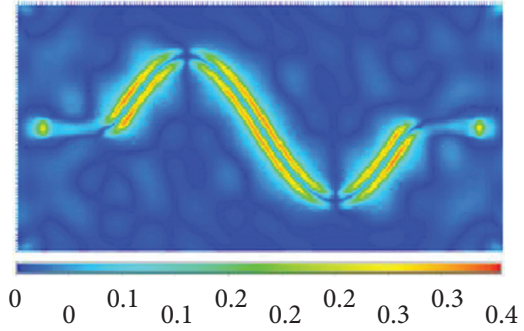

(a)

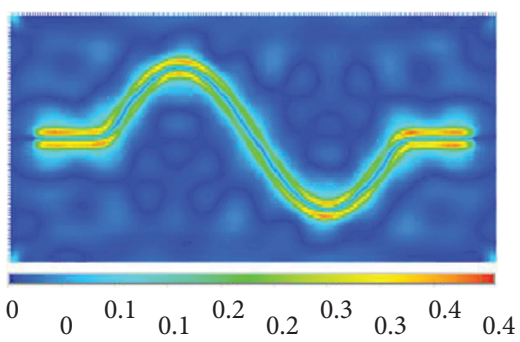

(b)

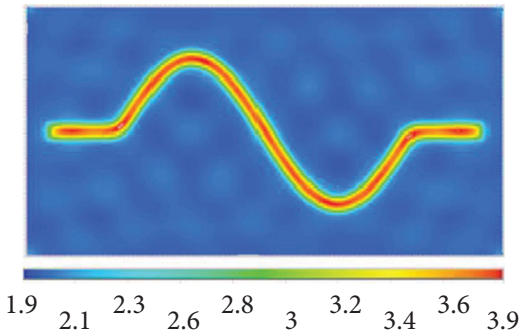

(c)

Figure 27: P wave incident $\left(H=100 \mathrm{~m}, f=2.0 \mathrm{~Hz}, C_{\mathrm{s}}=500 \mathrm{~m} / \mathrm{s}\right.$, and $\left.\mathrm{NR}=2\right)$. Top view displacement cloud view (a) $u_{x}$, (b) $u_{y}$, and (c) $u_{z}$.

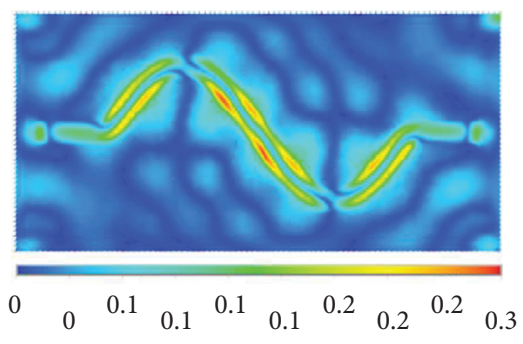

(a)

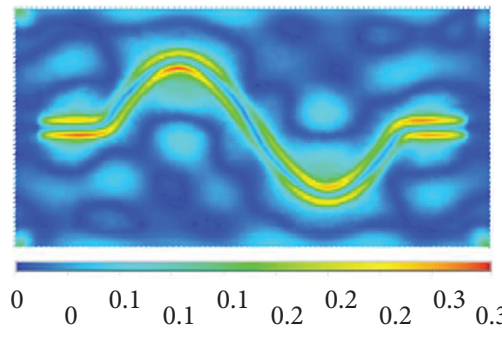

(b)

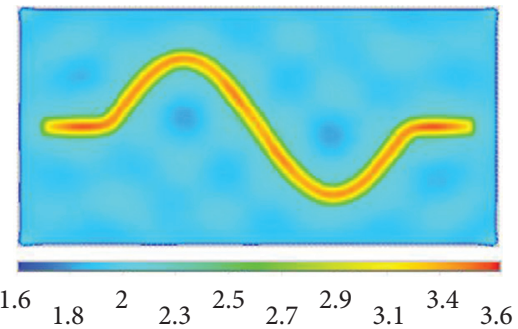

(c)

Figure 28: P wave incident $\left(H=125 \mathrm{~m}, f=2.0 \mathrm{~Hz}, C_{\mathrm{s}}=500 \mathrm{~m} / \mathrm{s}\right.$, and NR=2). Top view displacement cloud view (a) $u_{x}$, (b) $u_{y}$, and (c) $u_{z}$.

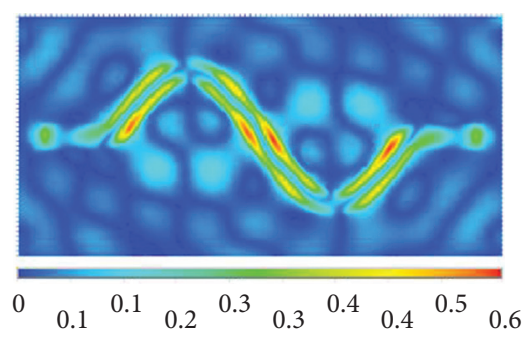

(a)

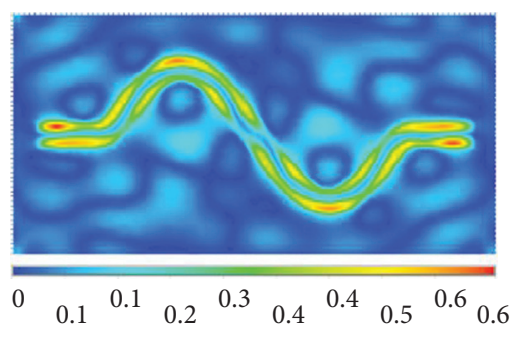

(b)

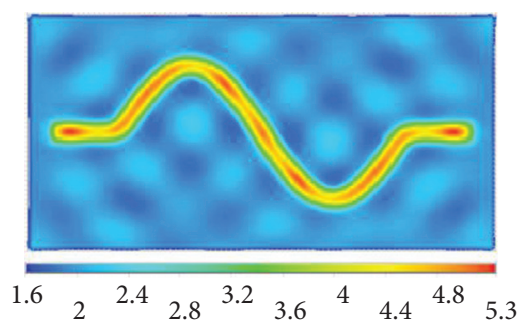

(c)

Figure 29: P wave incident $\left(H=150 \mathrm{~m}, f=2.0 \mathrm{~Hz}, C_{\mathrm{s}}=500 \mathrm{~m} / \mathrm{s}\right.$, and $\left.\mathrm{NR}=2\right)$. Top view displacement cloud view (a) $u_{x}$, (b) $u_{y}$, and (c) $u_{z}$.

small, such as $C_{\mathrm{s}}=300 \mathrm{~m} / \mathrm{s}$, the amplification of the main direction displacement is very significant and the surface displacement is about 9.1 times; when $C_{\mathrm{s}}=400 \mathrm{~m} / \mathrm{s}$, main direction displacement $U z$ increases $52.2 \%$ compared with $C_{\mathrm{s}}=600 \mathrm{~m} / \mathrm{s}$. At the same time, the whole vertical vibration of the winding river valley is displayed. The results indicate that the smaller the soil stiffness is, the larger the surface displacement amplitude of $\mathrm{P}$-wave ground motion can be.

For SV wave incident, the amplitude of surface displacement varies with soil stiffness, as shown in 


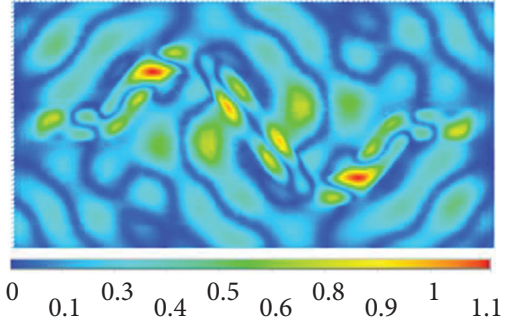

(a)

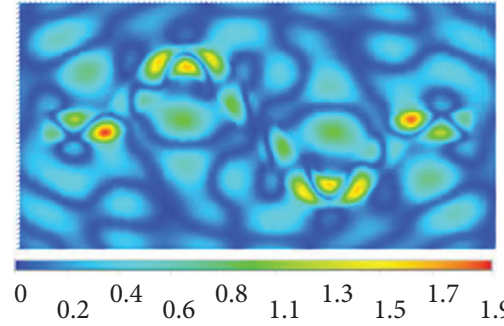

(b)

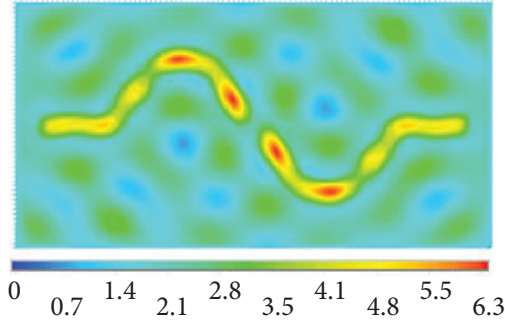

(c)

Figure 30: $P$ wave incident $\left(H=175 \mathrm{~m}, f=2.0 \mathrm{~Hz}, C_{\mathrm{s}}=500 \mathrm{~m} / \mathrm{s}\right.$, and $\left.\mathrm{NR}=2\right)$. Top view displacement cloud view (a) $u_{x}$, (b) $u_{y}$, and (c) $u_{z}$.

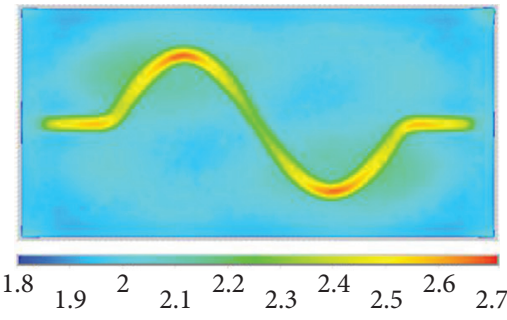

(a)

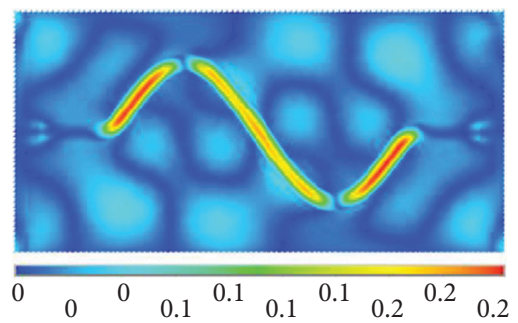

(b)

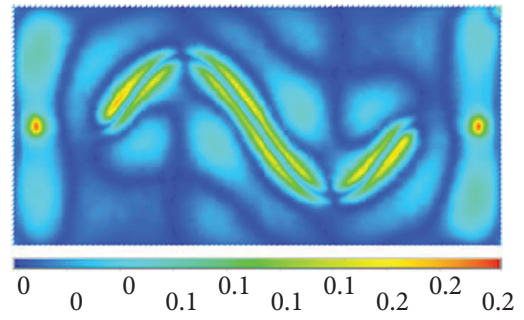

(c)

FIGURE 31: SV wave incident $\left(H=100 \mathrm{~m}, f=1.5 \mathrm{~Hz}, C_{\mathrm{s}}=500 \mathrm{~m} / \mathrm{s}\right.$, and NR=2). Top view displacement cloud view (a) $u_{x}$, (b) $u_{y}$, and (c) $u_{z}$.
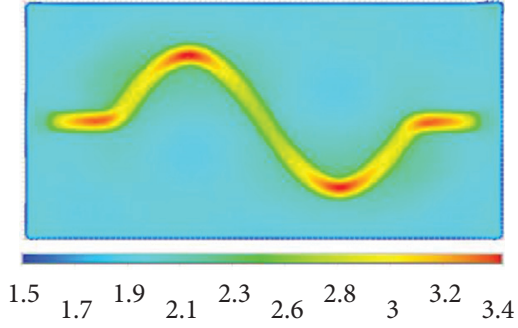

(a)

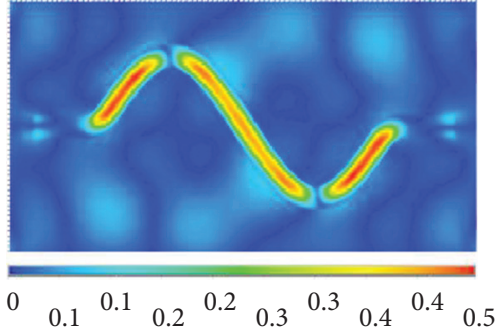

(b)

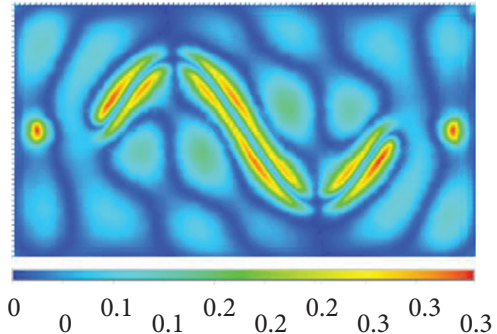

(c)

Figure 32: SV wave incident $\left(H=125 \mathrm{~m}, f=1.5 \mathrm{~Hz}, C_{\mathrm{s}}=500 \mathrm{~m} / \mathrm{s}\right.$, and NR=2). Top view displacement cloud view (a) $u_{x}$, (b) $u_{y}$, and (c) $u_{z}$.

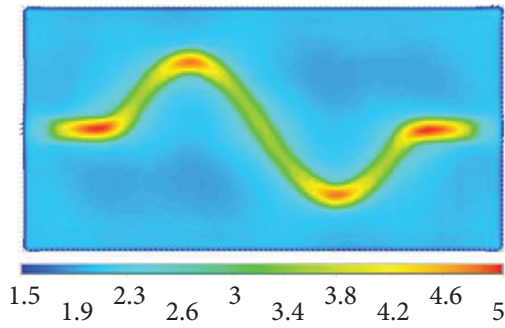

(a)

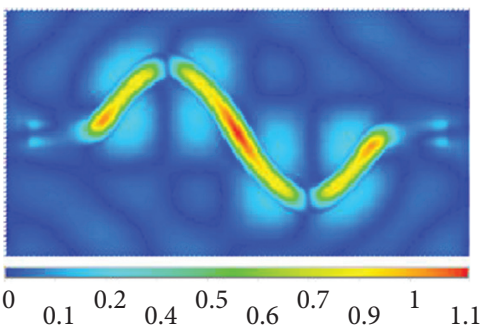

(b)

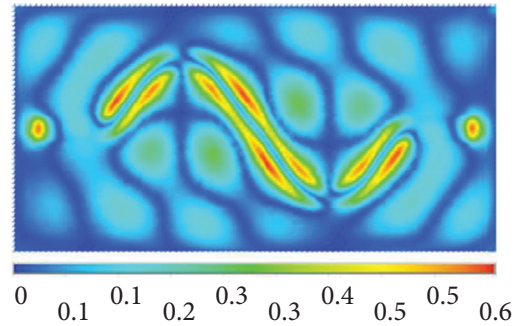

(c)

Figure 33: SV wave incident $\left(H=150 \mathrm{~m}, f=1.0 \mathrm{~Hz}, C_{\mathrm{s}}=500 \mathrm{~m} / \mathrm{s}\right.$, and $\left.\mathrm{NR}=2\right)$. Top view displacement cloud view (a) $u_{x}$, (b) $u_{y}$, and (c) $u_{z}$.

Figures 43-46. It can be seen that, as the soil stiffness is smaller when an SV wave is incident, the surface displacement in three directions has an obvious amplification effect.
When the soil stiffness is large $\left(C_{\mathrm{s}}>500 \mathrm{~m} / \mathrm{s}\right)$, the spatial distribution of surface displacement does not change and the displacement amplitude changes significantly. For example, the displacement amplitude of $C_{\mathrm{s}}=500 \mathrm{~m} / \mathrm{s}$ in the main 


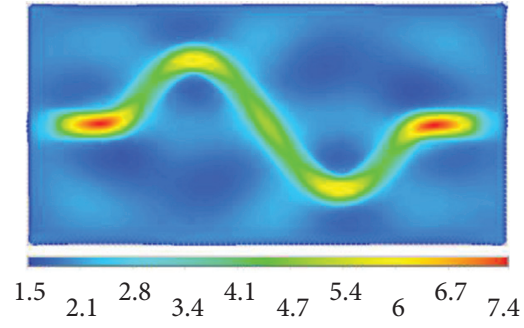

(a)

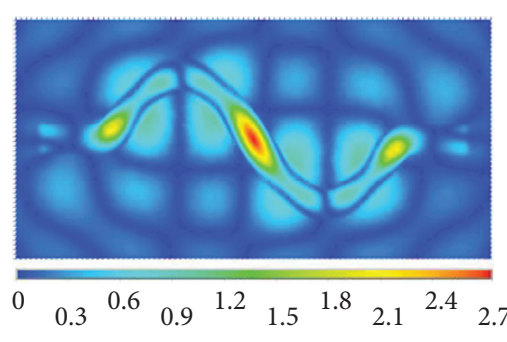

(b)

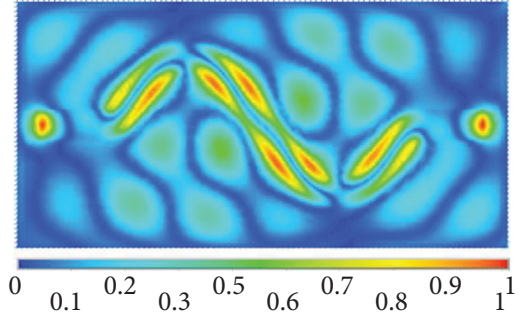

(c)

FiguRe 34: SV wave incident $\left(H=175 \mathrm{~m}, f=1.5 \mathrm{~Hz}, C_{\mathrm{s}}=500 \mathrm{~m} / \mathrm{s}\right.$, and $\left.\mathrm{NR}=2\right)$. Top view displacement cloud view (a) $u_{x}$, (b) $u_{y}$, and (c) $u_{z}$.

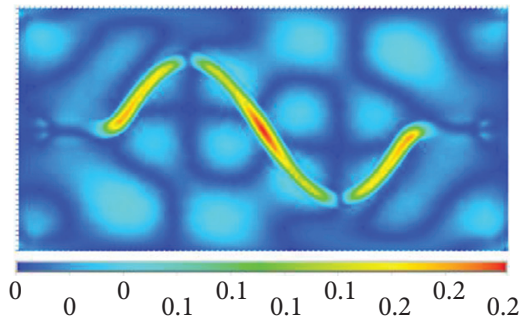

(a)

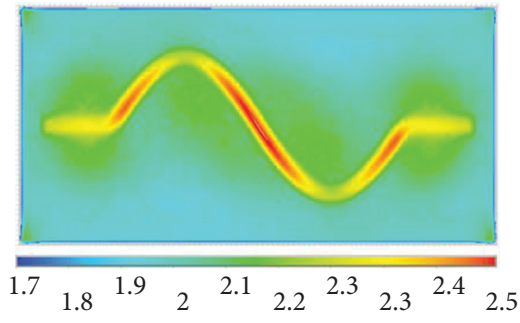

(b)

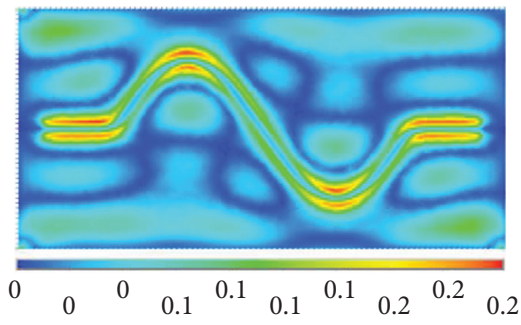

(c)

Figure 35: SH wave incident $\left(H=100 \mathrm{~m}, f=1.0 \mathrm{~Hz}, C_{\mathrm{s}}=500 \mathrm{~m} / \mathrm{s}\right.$, and NR=2). Top view displacement cloud view (a) $u_{x}$, (b) $u_{y}$, and (c) $u_{z}$.

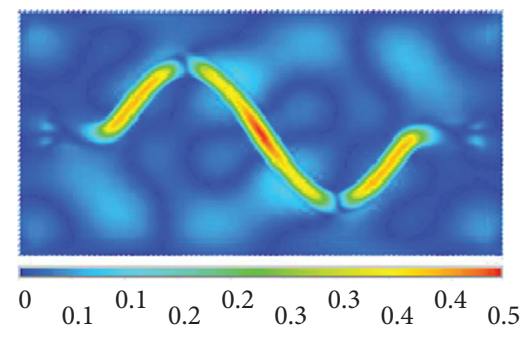

(a)

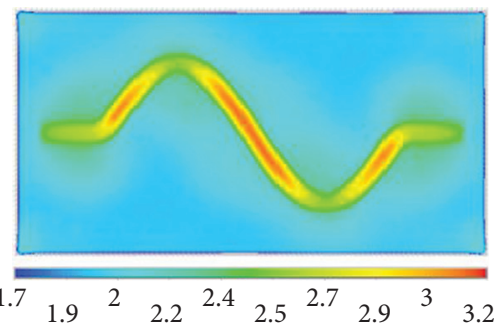

(b)

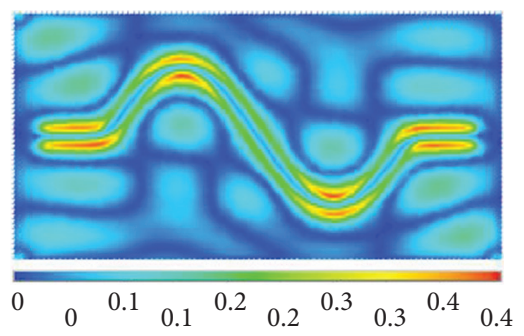

(c)

Figure 36: SH wave incident $\left(H=125 \mathrm{~m}, f=1.0 \mathrm{~Hz}, C_{\mathrm{s}}=500 \mathrm{~m} / \mathrm{s}\right.$, and $\left.\mathrm{NR}=2\right)$. Top view displacement cloud view (a) $u_{x}$, (b) $u_{y}$, and (c) $u_{z}$.

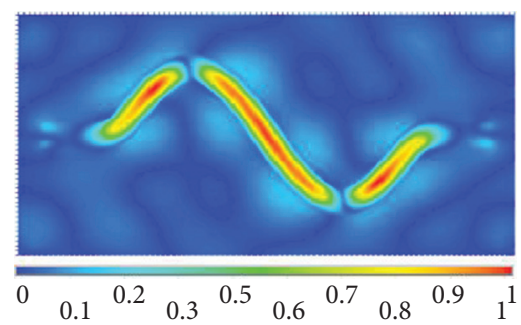

(a)

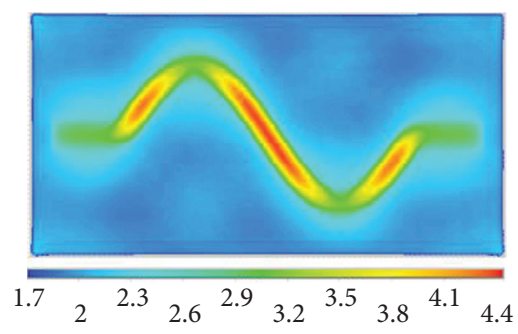

(b)

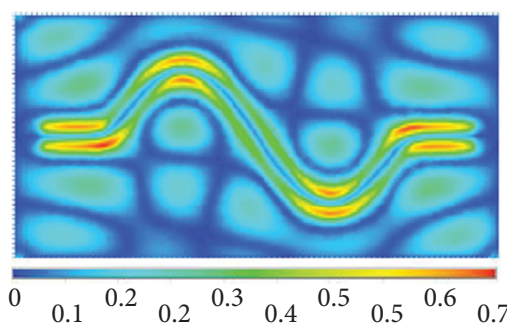

(c)

Figure 37: SH wave incident $\left(H=150 \mathrm{~m}, f=1.0 \mathrm{~Hz}, C_{\mathrm{s}}=500 \mathrm{~m} / \mathrm{s}\right.$, and $\left.\mathrm{NR}=2\right)$. Top view displacement cloud view (a) $u_{x}$, (b) $u_{y}$, and (c) $u_{z}$.

direction $U x$ increases by $81.8 \%$ compared with $C_{\mathrm{s}}=600 \mathrm{~m} / \mathrm{s}$. The displacement amplitude $U y$ of $C_{\mathrm{s}}=500 \mathrm{~m} / \mathrm{s}$ is increased by $150 \%$ compared with $C_{\mathrm{s}}=600 \mathrm{~m} / \mathrm{s}$. When the soil stiffness is small $\left(C_{\mathrm{s}}<500 \mathrm{~m} / \mathrm{s}\right)$, because of the coherent action of the river valley, the displacement of the area near the winding corner weakens to about 0 . It is worth noting that the amplification effect of wave velocity in lower soil layer on ground motion is very obvious. When $C_{\mathrm{s}}=300 \mathrm{~m} / \mathrm{s}$, the amplification of displacement in the main direction is nearly 11.6 times and the amplification in the secondary direction is also obvious, with $U y$ as high as 11.6 and $U z$ as high as 7.1, which fully indicates that the incident wave will have a 


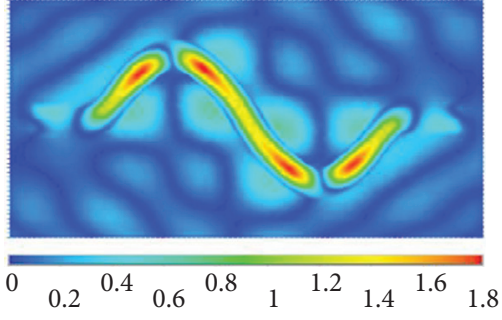

(a)

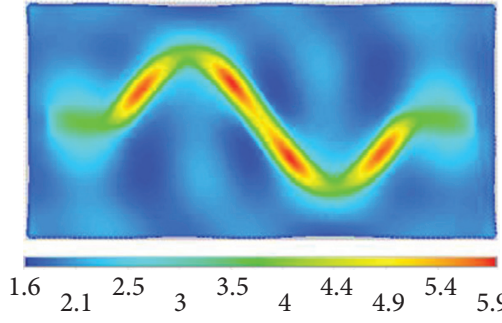

(b)

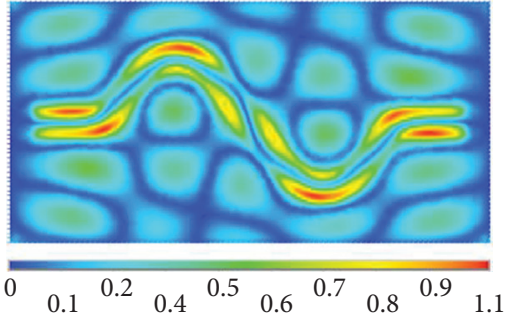

(c)

FiguRe 38: SH wave incident $\left(C_{\mathrm{s}}=500 \mathrm{~m} / \mathrm{s}, f=1.0 \mathrm{~Hz}, H=175 \mathrm{~m}\right.$, and $\left.\mathrm{NR}=2\right)$. Top view displacement cloud view (a) $u_{x}$, (b) $u_{y}$, and (c) $u_{z}$.

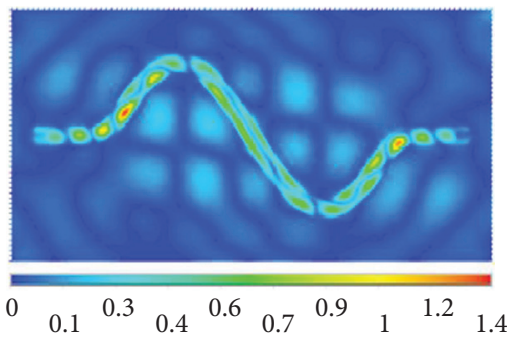

(a)

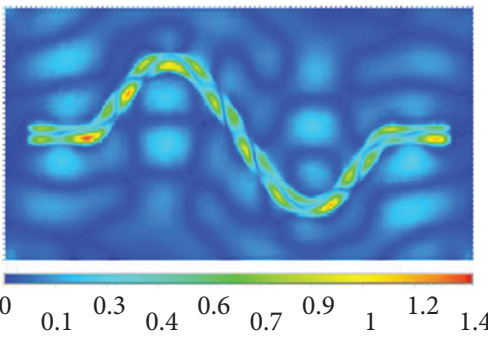

(b)

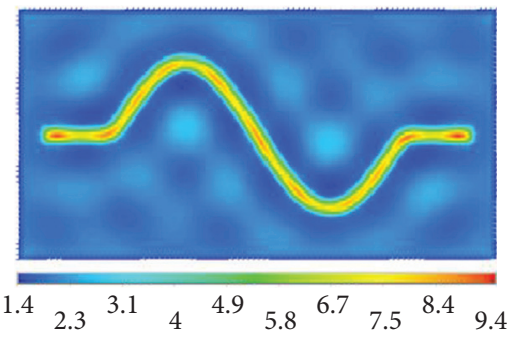

(c)

Figure 39: P wave incident $\left(C_{s}=300 \mathrm{~m} / \mathrm{s}, f=2.0 \mathrm{~Hz}, H=100 \mathrm{~m}\right.$, and $\left.\mathrm{NR}=2\right)$. Top view displacement cloud view (a) $u_{x}$, (b) $u_{y}$, and (c) $u_{z}$.

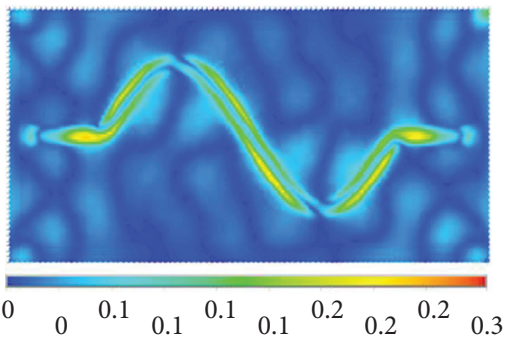

(a)

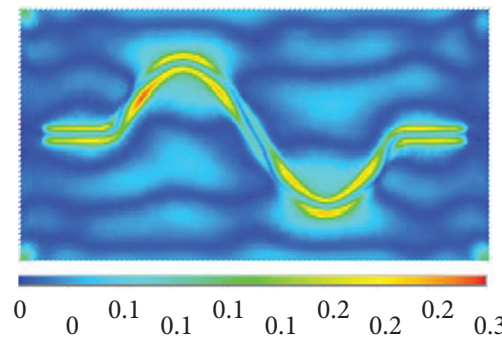

(b)

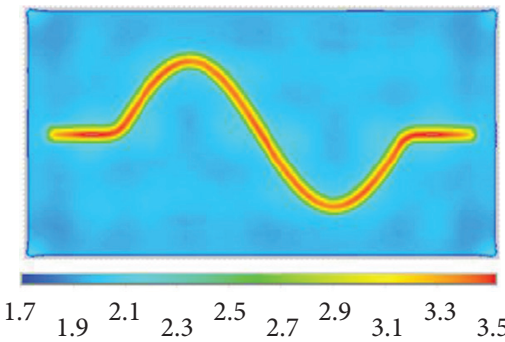

(c)

Figure 40: P wave incident $\left(C_{s}=400 \mathrm{~m} / \mathrm{s}, f=2.0 \mathrm{~Hz}, H=100 \mathrm{~m}\right.$, and $\left.\mathrm{NR}=2\right)$. Top view displacement cloud view (a) $u_{x}$, (b) $u_{y}$, and (c) $u_{z}$.

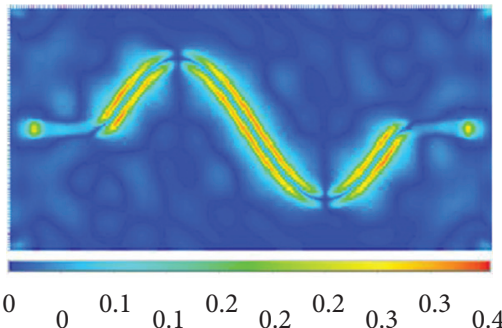

(a)
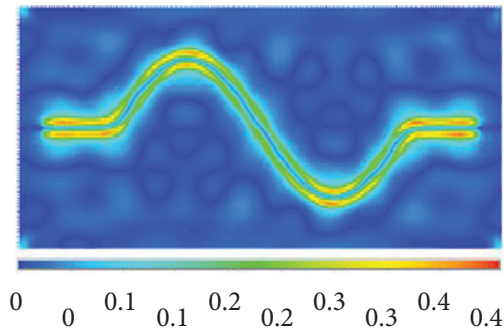

(b)

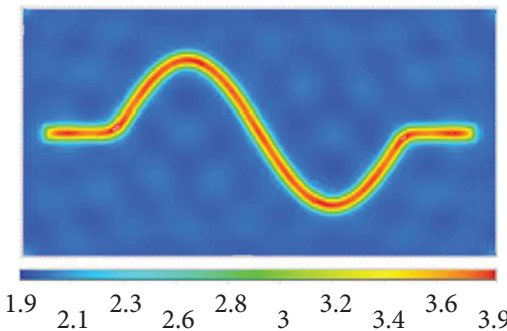

(c)

Figure 41: P wave incident $\left(C_{s}=500 \mathrm{~m} / \mathrm{s}, f=2.0 \mathrm{~Hz}, H=100 \mathrm{~m}\right.$, and $\left.\mathrm{NR}=2\right)$. Top view displacement cloud view (a) $u_{x}$, (b) $u_{y}$, and (c) $u_{z}$.

strong coherent effect in the low wave velocity soil layer, and the surface displacement is significantly amplified. It is fully indicated that the increase of the stiffness ratio of bedrock to soil layer will significantly increase the surface displacement amplitude of the meandering valley.
Since SH wave is incident, as shown in Figures 47-50 for the surface displacement amplitude with the change rule of soil stiffness, it can be found that, consistent with the incidence of SV waves, the smaller the stiffness of the soil, the greater the magnification effect of the surface displacement 


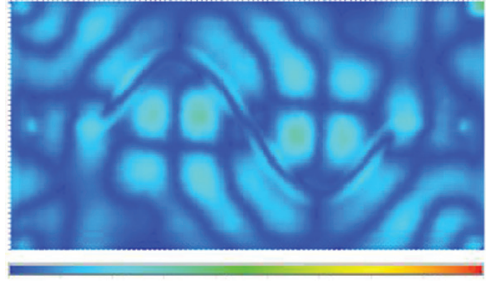

$\begin{array}{lllllllllll}0 & 0 & 0.1 & 0.1 & 0.1 & 0.1 & 0.2 & 0.2 & 0.2 & 0.3\end{array}$

(a)

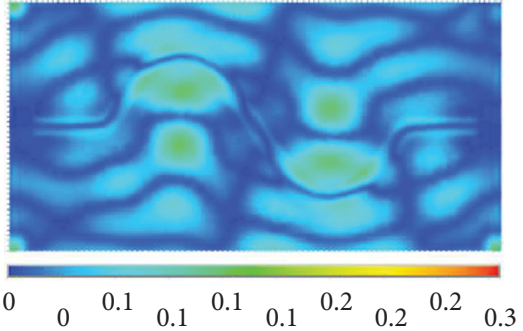

(b)

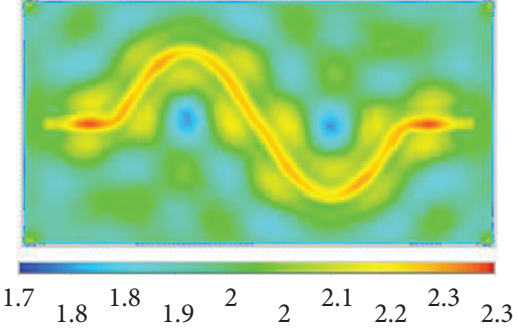

(c)

Figure 42: $P$ wave incident $\left(C_{s}=600 \mathrm{~m} / \mathrm{s}, f=2.0 \mathrm{~Hz}, H=100 \mathrm{~m}\right.$, and $\left.\mathrm{NR}=2\right)$. Top view displacement cloud view (a) $u_{x}$, (b) $u_{y}$, and (c) $u_{z}$.

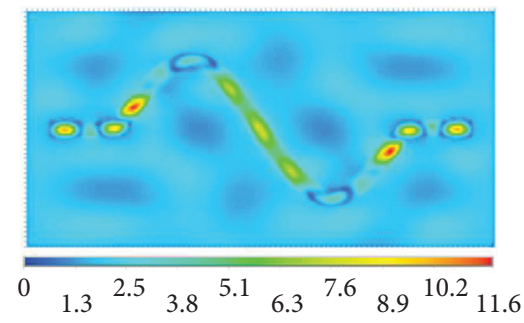

(a)

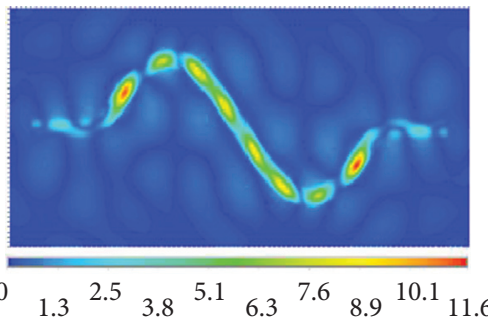

(b)

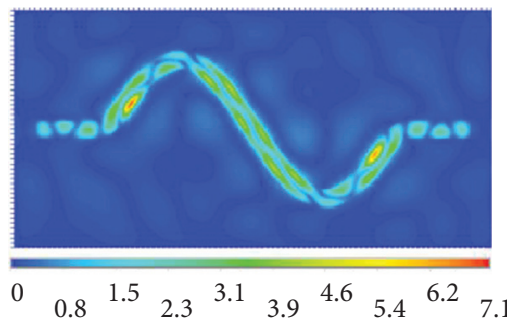

(c)

FiguRE 43: SV wave incident $\left(C_{\mathrm{s}}=300 \mathrm{~m} / \mathrm{s}, f=1.5 \mathrm{~Hz}, H=100 \mathrm{~m}\right.$, and $\left.\mathrm{NR}=2\right)$. Top view displacement cloud view (a) $u_{x}$, (b) $u_{y}$, and (c) $u_{z}$.
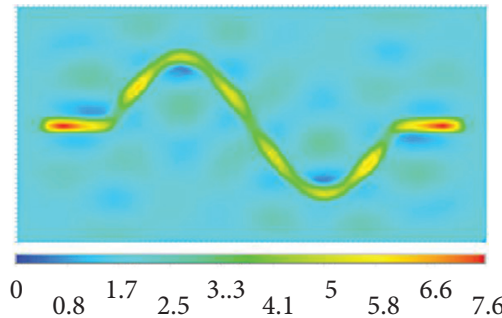

(a)

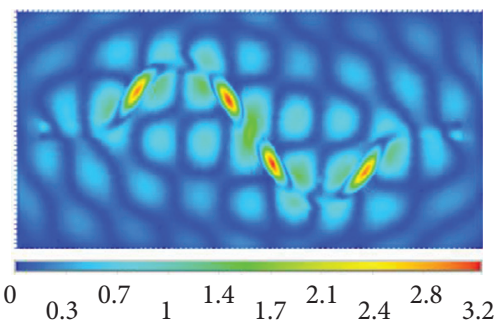

(b)

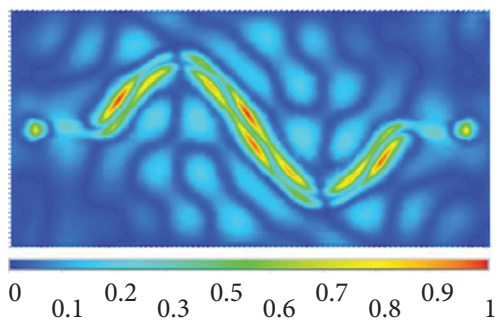

(c)

Figure 44: SV wave incident $\left(C_{\mathrm{s}}=400 \mathrm{~m} / \mathrm{s}, f=1.5 \mathrm{~Hz}, H=100 \mathrm{~m}\right.$, and $\left.\mathrm{NR}=2\right)$. Top view displacement cloud view (a) $u_{x}$, (b) $u_{y}$, and (c) $u_{z}$.

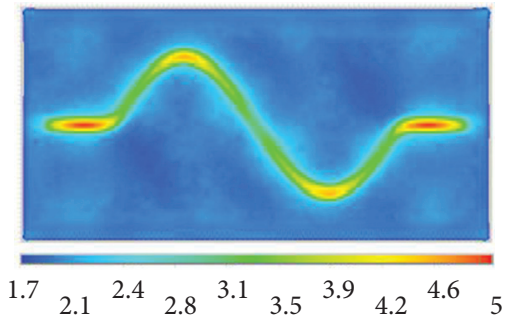

(a)

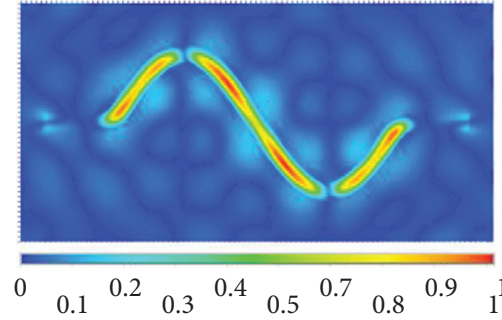

(b)

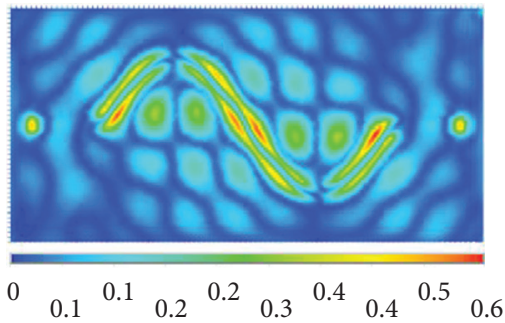

(c)

Figure 45: SV wave incident $\left(C_{\mathrm{s}}=500 \mathrm{~m} / \mathrm{s}, f=1.5 \mathrm{~Hz}, H=100 \mathrm{~m}\right.$, and NR=2). Top view displacement cloud view (a) $u_{x}$, (b) $u_{y}$, and (c) $u_{z}$.

in the three directions. It is worth noting that when the $\mathrm{SH}$ wave is incident, the magnification and position of the ground displacement are significantly different from that of the SV. Similarly, when the soil stiffness is small $\left(C_{\mathrm{s}}<500 \mathrm{~m} /\right.$ $s)$, the amplification effect of wave velocity on ground motion in low soil layer is significant. When $C_{\mathrm{s}}=300 \mathrm{~m} / \mathrm{s}$, the displacement in three directions increases significantly and presents different manifestations. The displacement amplification in the main direction $U x$ is significant near $x=3400 \mathrm{~m}$ and $x=6200 \mathrm{~m}$, and the peak value is as high as 16.9. The displacement amplitude of $U y$ and $U z$ is up to 12 and 7.2, respectively. When the soil stiffness is large 
$\left(C_{\mathrm{s}}>500 \mathrm{~m} / \mathrm{s}\right)$, the spatial distribution of surface displacement does not change and the displacement amplitude changes significantly. For example, the displacement amplitude $U y$ in the main direction of $C_{\mathrm{s}}=500 \mathrm{~m} / \mathrm{s}$ increases by $37.9 \%$ compared with that of $C_{\mathrm{s}}=600 \mathrm{~m} / \mathrm{s}$. The displacement amplitude of $C_{\mathrm{s}}=500 \mathrm{~m} / \mathrm{s}$ is $150 \%$ higher than that of $C_{\mathrm{s}}=600 \mathrm{~m} / \mathrm{s}$. Again, it fully shows that the incident wave has a strong, coherent effect in the soil layer with low wave velocity and the surface displacement is significantly amplified. It is fully indicated that the increase of the stiffness ratio of bedrock to soil layer will significantly increase the surface displacement amplitude of the meandering valley.

4.4. The Influence of the Number of Valley Meanders. It is worth noting that the number of bends in meandering sedimentary valleys may have a certain influence on seismic fluctuations, and take the same radius of three-dimensional hemisphere sedimentary basins with the different numbers of the winding valley site for contrast analysis; the threedimensional hemisphere sedimentary basin radius $R=100 \mathrm{~m}$, meandering river sedimentary depth $H=100 \mathrm{~m}$, P-wave analysis of incident wave frequency $f=2.0 \mathrm{~Hz}$, and SV and SH wave analysis takes $f=2.0 \mathrm{~Hz}$ to study the surface displacement amplitude of three-dimensional hemispheric sedimentary basins with different sinuous numbers. From Figures 3-48 to Figures 3-53, we can see the overlooking cloud diagram of surface displacement amplitude of a uniformly deposited valley site with different sinuous numbers $(\mathrm{NR}=1, \mathrm{NR}=2$, and $\mathrm{NR}=3)$ under incident frequencies of $\mathrm{P}, \mathrm{SV}$, and $\mathrm{SH}$ waves. Figures 51-54 show the surface displacement amplitude of $\mathrm{P}$ wave, Figures 55-58 show the surface displacement amplitude of SV wave, and Figures 59-62 show the surface displacement amplitude of $\mathrm{SH}$ wave. It can be seen from the figures that regardless of $\mathrm{P}$, $\mathrm{SV}$, or SH waves, the surface displacement amplitudes of meandering valley sites are significantly different from those of hemispheric sedimentary basins, but the number of meandering has little influence on the surface displacement amplitudes. Studying valley sites with different numbers of meandering helps to understand the surface displacement of their meandering valley terrain in the meandering curve section.

Figure 51 shows the amplitude cloud of surface displacement of a three-dimensional hemispheric sedimentary basin under $\mathrm{P}$-wave incidence. The main direction $U z$ shows the focal amplification effect of the basin center, while the secondary direction $U x$ and $U y$ show the amplification effect of the basin edge. Figure 52 number as shown in Figure 54 for different sedimentary valley overlooking the contours of the surface displacement amplitude from which you can see, winding valley and depositing hemisphere form, presents the main direction $U z$ center is focused on the amplification, presents the $U x$ direction displacement and $U y$ edge effect, and different sedimentary valley winding numbers showing a consistent form of surface displacement. It can be seen from the figures that, under the incident of $\mathrm{P}$ wave, the displacement amplitude of $U z$ in the main direction of the sinuous sedimentary valley increases by about $25 \%$ compared with the basin in the sedimentary hemisphere, the displacement in the secondary direction $U x$ increases by $100 \%$, and the displacement in the secondary direction $U y$ increases by $33 \%$.

Figure 55 shows the amplitude cloud of surface displacement in a three-dimensional hemispheric sedimentary basin under SV wave incidence. Similarly, the amplitude of surface displacement in the main direction $U x$ shows the focal amplification effect in the center of the basin, and the amplitude of surface displacement is 2.6. The secondary direction displacement $U y$ shows the focal amplification in the periphery of the basin, and the secondary direction displacement $U z$ shows the focal amplification in the center of the basin. Figures 56-58 show the overhead cloud diagrams of surface displacement amplitudes of sedimentary valleys with different winding numbers, from which it can be seen that similar to the $\mathrm{P}$ wave, surface displacement of sedimentary valleys with different winding numbers presents basically the same form of expression. As can be seen from the figures, under SV wave incidence, $U x$ in the main direction of the meandering river valley shows significant displacement amplification near the straight-line segment and the meandering corner, showing a central focusing effect. The secondary displacement $U y$ shows that the focal amplification is significant in the valley center of each meandering section. The secondary direction displacement $U z$ shows the edge effect, and the displacement of both sides of the valley is obviously amplified. At the same time, the curved valley on both sides of the displacement $U z$ exists the multipoint focusing amplification effect in the semispace site near the edge of the valley due to the waveform transformation and diffraction, scattering, and other effects, and the focusing area shows the left and right symmetry in the overlooking cloud image.

As can be seen from the figures compared with the threedimensional sedimentary hemispheric basin, under SV wave incidence, the displacement amplitude of sinuous sedimentary valley in the main direction $U x$ is twice that of the sedimentary hemispheric basin and the displacement in the secondary direction $U z$ is 1.5 times that of the sedimentary hemispheric basin. Compared with the hemispheric sedimentary basin, the displacement in the secondary direction $U y$ is more significant and magnified by about 12 times.

Figure 59 shows the amplitude cloud of surface displacement in a three-dimensional hemispheric sedimentary basin under $\mathrm{SH}$ wave incidence. The amplitude of surface displacement under $\mathrm{SH}$ wave incidence is consistent with that under SV wave incidence. Figures 59-62 show overhead cloud pictures of surface displacement amplitude of sedimentary valleys with different sinuous numbers. It is worth noting that the site of sinuous valleys is different from that of sedimentary basins in that the manifestation of surface displacement under $\mathrm{SH}$ wave incidence is different from that under SV wave incidence. The main direction $U y$ in the main direction of the meandering river valley shows significant displacement amplification in the meandering curves' segment (except around the meandering corner), showing a central-focusing effect. The secondary displacement $U x$ is consistent with the major displacement amplification. Unlike the incidence of SV waves, the surface displacement of the zigzag valley section is 


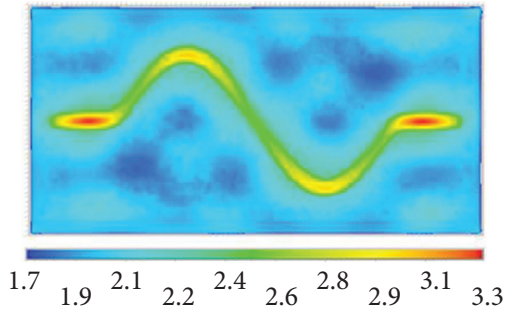

(a)

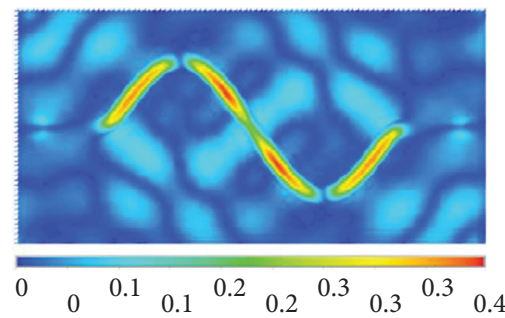

(b)

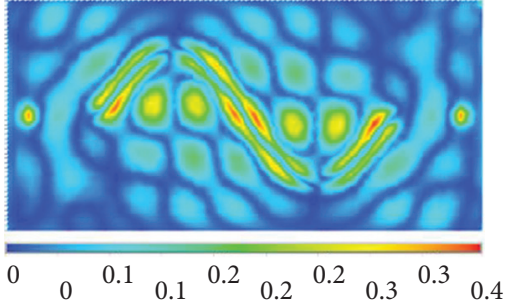

(c)

Figure 46: SV wave incident $\left(C_{\mathrm{s}}=600 \mathrm{~m} / \mathrm{s}, f=1.5 \mathrm{~Hz}, H=100 \mathrm{~m}\right.$, and NR=2). Top view displacement cloud view (a) $u_{x}$, (b) $u_{y}$, and (c) $u_{z}$.

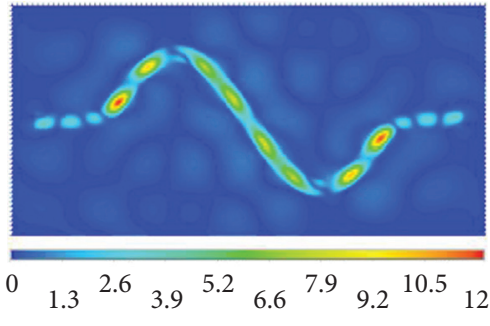

(a)

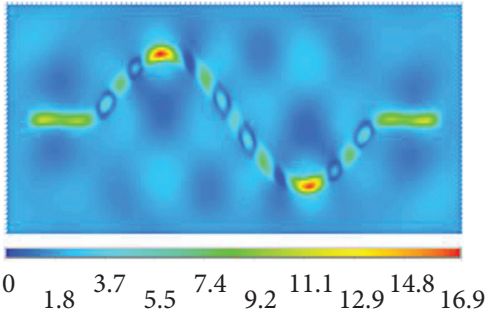

(b)

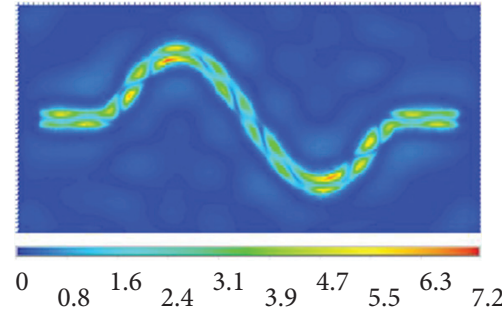

(c)

Figure 47: SH wave incident $\left(C_{\mathrm{s}}=300 \mathrm{~m} / \mathrm{s}, f=2.0 \mathrm{~Hz}, H=100 \mathrm{~m}\right.$, and $\left.\mathrm{NR}=2\right)$. Top view displacement cloud view (a) $u_{x}$, (b) $u_{y}$, and (c) $u_{z}$.

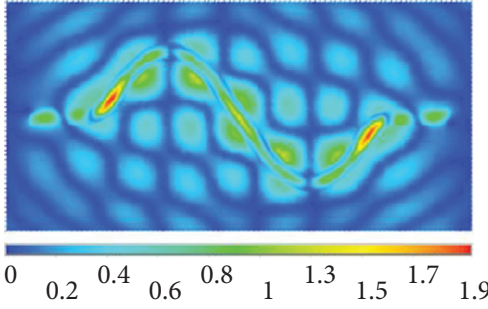

(a)

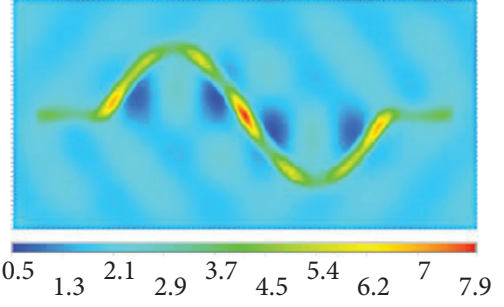

(b)

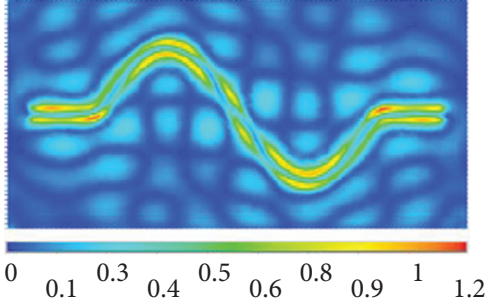

(c)

Figure 48: SH wave incident $\left(C_{\mathrm{s}}=400 \mathrm{~m} / \mathrm{s}, f=2.0 \mathrm{~Hz}, H=100 \mathrm{~m}\right.$, and $\left.\mathrm{NR}=2\right)$. Top view displacement cloud view (a) $u_{x}$, (b) $u_{y}$, and (c) $u_{z}$.

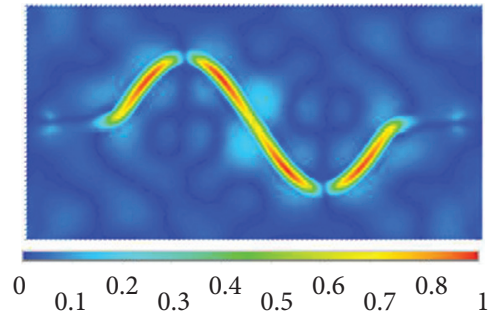

(a)

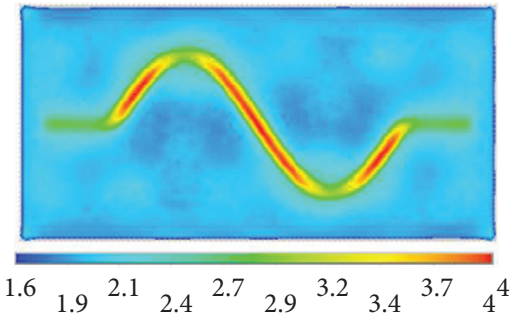

(b)

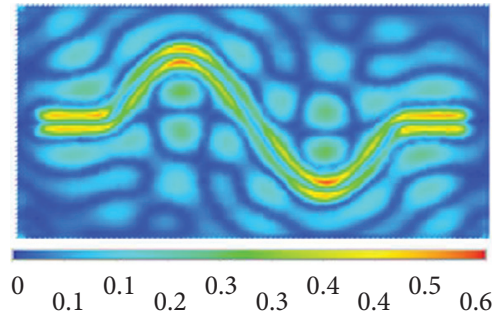

(c)

Figure 49: SH wave incident $\left(C_{\mathrm{s}}=500 \mathrm{~m} / \mathrm{s}, f=2.0 \mathrm{~Hz}, H=100 \mathrm{~m}\right.$, and NR=2). Top view displacement cloud view (a) $u_{x}$, (b) $u_{y}$, and (c) $u_{z}$.

significant. This is because the $\mathrm{SH}$ wave vibrates along the $\mathrm{y}$ axis, and the waveforms in the curved river valley on both sides of the zigzag and related effects such as waveform conversion, scattering, and diffraction occur. The half space near the river valley also has a certain amplification effect. It can be seen from the figures that compared with the three-dimensional sedimentary hemispheric basin, the displacement amplitude of the sinuous sedimentary valley in the main direction $U y$ is 1.7 times that of the sedimentary hemispheric basin under $\mathrm{SH}$ wave incidence and the displacement $U z$ in the secondary direction is 1.5 times that of the sedimentary hemispheric basin. Compared with the hemispheric sedimentary basin, the displacement $U x$ in the secondary direction is more significant and magnified by about 11 times. 


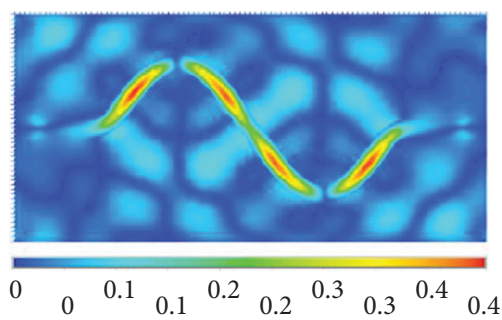

(a)

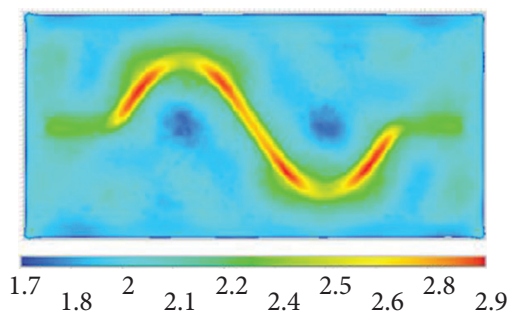

(b)

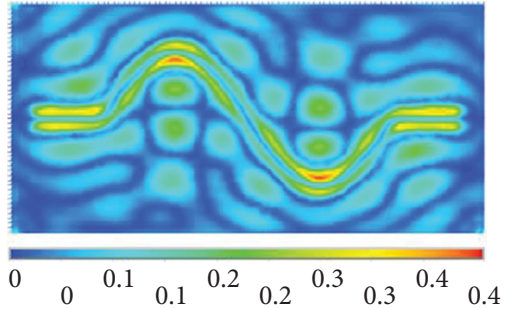

(c)

Figure 50: SH wave incident $\left(f=2.0 \mathrm{~Hz}, H=100 \mathrm{~m}\right.$, and $\left.C_{\mathrm{s}}=600 \mathrm{~m} / \mathrm{s}, \mathrm{NR}=2\right)$. Top view displacement cloud view (a) $u_{x}$, (b) $u_{y}$, and (c) $u_{z}$.

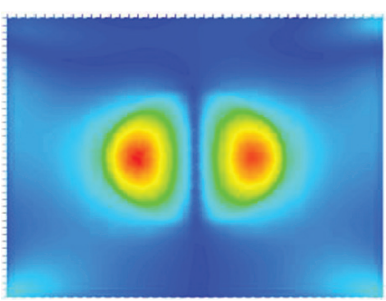

(a)

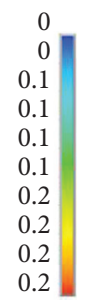

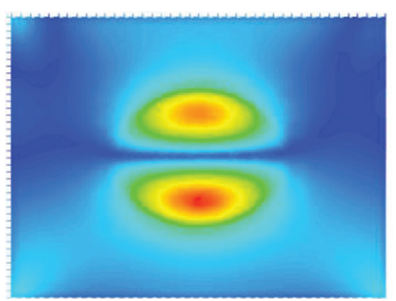

(b)

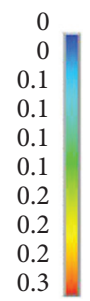

0.3

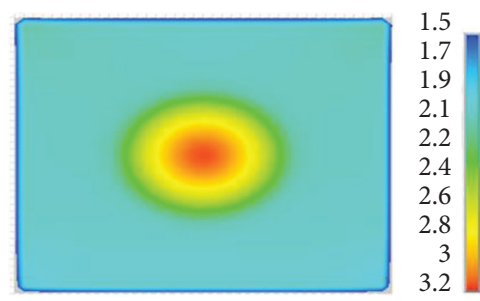

(c)

Figure 51: $P$ wave incident (3D sedimentary hemispheric basin, $f=2.0 \mathrm{~Hz}, R=100 \mathrm{~m}, C_{s}=500 \mathrm{~m} / \mathrm{s}$ ). Top view displacement cloud view (a) $u_{x}$, (b) $u_{y}$, (c) $u_{z}$.

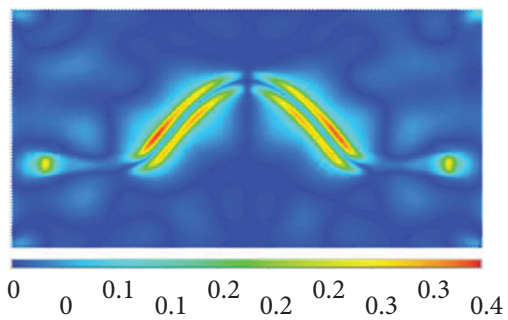

(a)

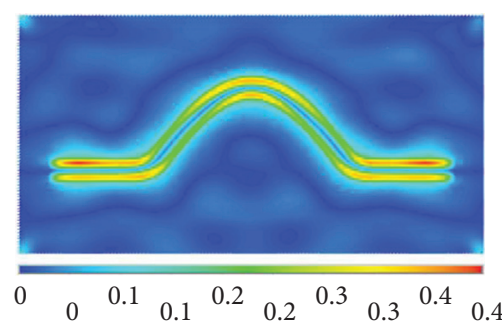

(b)

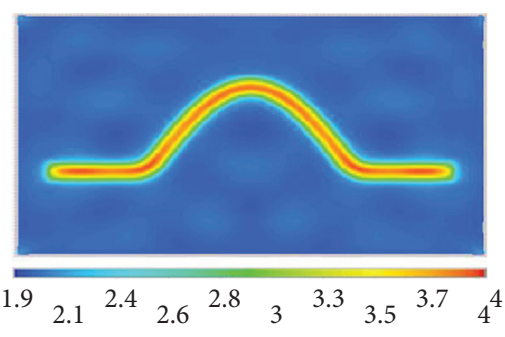

(c)

Figure 52: $\mathrm{P}$ wave incident $\left(\mathrm{NR}=1, f=2.0 \mathrm{~Hz}, H=100 \mathrm{~m}\right.$, and $\left.C_{\mathrm{s}}=500 \mathrm{~m} / \mathrm{s}\right)$. Top view displacement cloud view (a) $u_{x}$, (b) $u_{y}$, and (c) $u_{z}$.

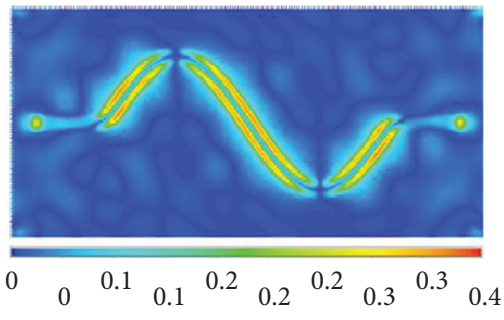

(a)

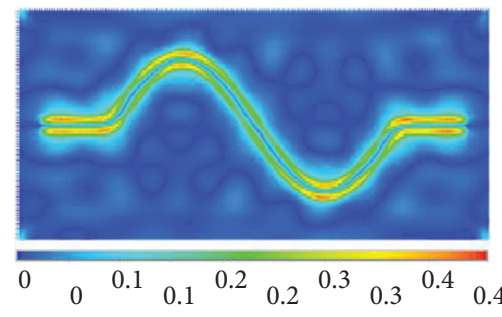

(b)

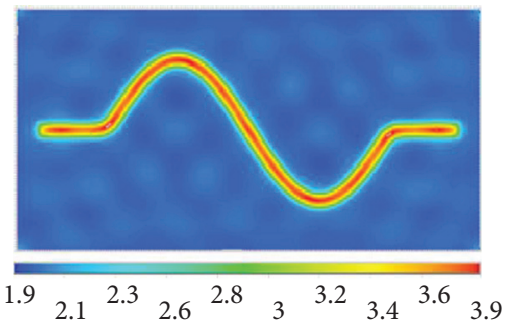

(c)

Figure 53: P wave incident $\left(\mathrm{NR}=2, f=2.0 \mathrm{~Hz}, H=100 \mathrm{~m}\right.$, and $\left.C_{\mathrm{s}}=500 \mathrm{~m} / \mathrm{s}\right)$. Top view displacement cloud view (a) $u_{x}$, (b) $u_{y}$, and (c) $u_{z}$. 


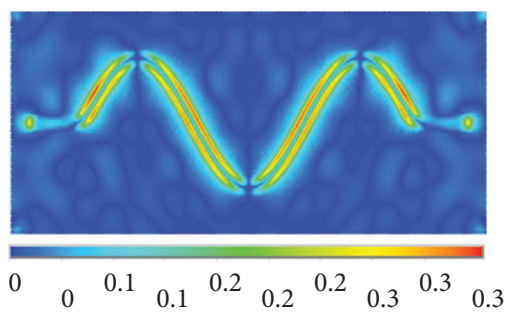

(a)

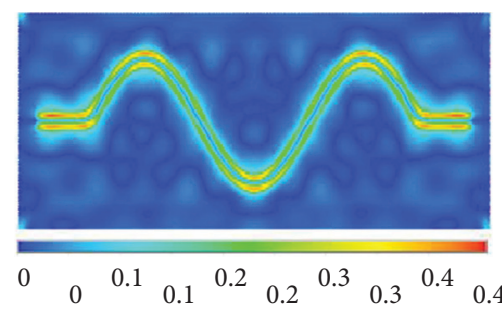

(b)

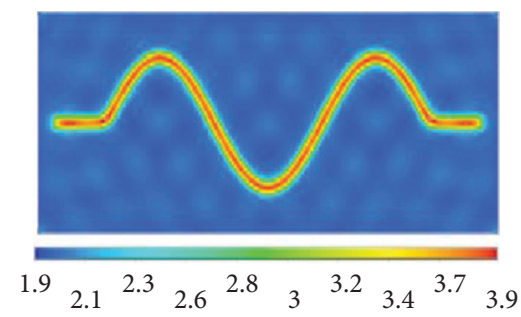

(c)

Figure 54: $\mathrm{P}$ wave incident $\left(\mathrm{NR}=3, f=2.0 \mathrm{~Hz}, H=100 \mathrm{~m}\right.$, and $\left.C_{\mathrm{s}}=500 \mathrm{~m} / \mathrm{s}\right)$. Top view displacement cloud view (a) $u_{x}$, (b) $u_{y}$, and (c) $u_{z}$.

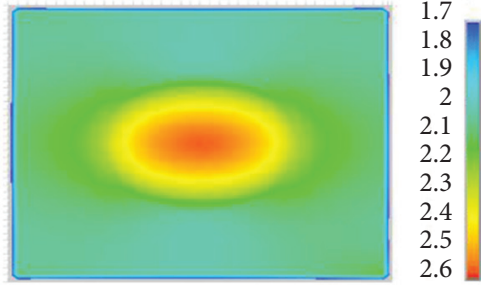

(a)

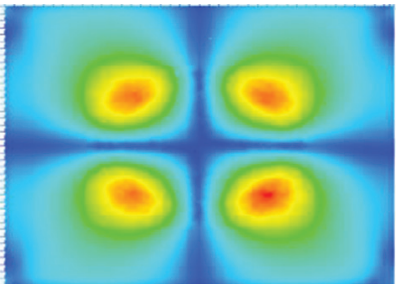

(b)
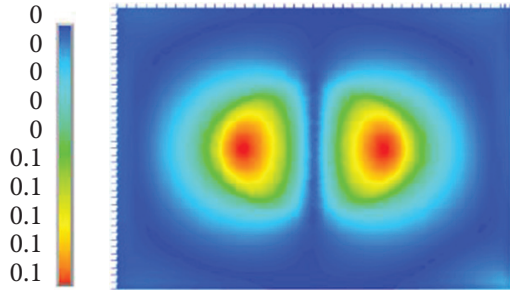

(c)

Figure 55: SV wave incident (3D sedimentary hemispheric basin, $f=1.5 \mathrm{~Hz}, R=100 \mathrm{~m}$, and $C_{\mathrm{s}}=500 \mathrm{~m} / \mathrm{s}$ ). Top view displacement cloud view (a) $u_{x}$, (b) $u_{y}$, and (c) $u_{z}$.

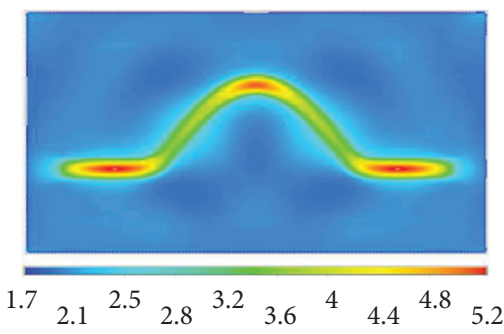

(a)

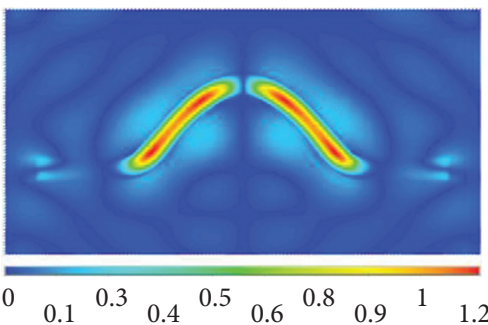

(b)

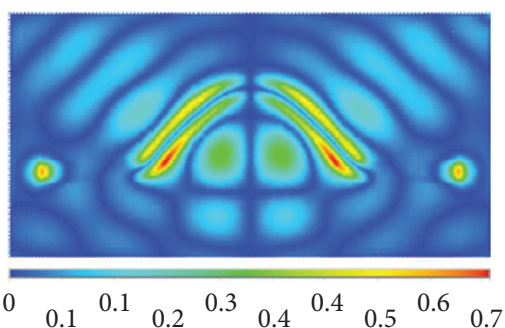

(c)

Figure 56: SV wave incident $\left(\mathrm{NR}=1, f=1.5 .0 \mathrm{~Hz}, H=100 \mathrm{~m}\right.$, and $\left.C_{\mathrm{s}}=500 \mathrm{~m} / \mathrm{s}\right)$. Top view displacement cloud view (a) $u_{x}$, (b) $u_{y}$, and (c) $u_{z}$.

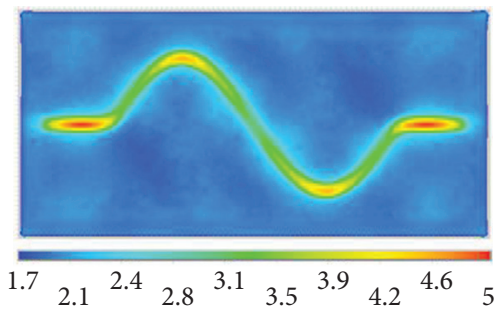

(a)

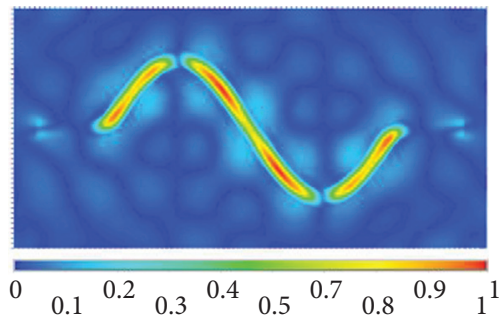

(b)

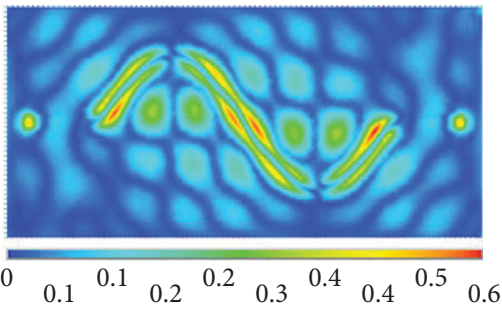

(c)

FiguRE 57: SV wave incident $\left(\mathrm{NR}=2, f=1.5 \mathrm{~Hz}, H=100 \mathrm{~m}\right.$, and $\left.C_{\mathrm{s}}=500 \mathrm{~m} / \mathrm{s}\right)$. Top view displacement cloud view (a) $u_{x}$, (b) $u_{y}$, and (c) $u_{z}$. 


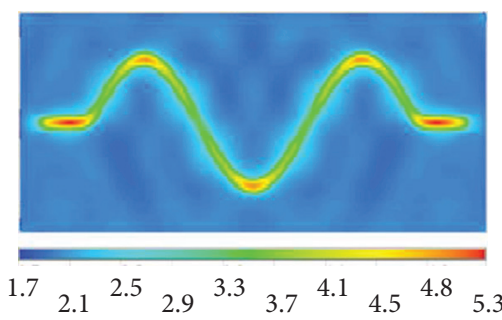

(a)

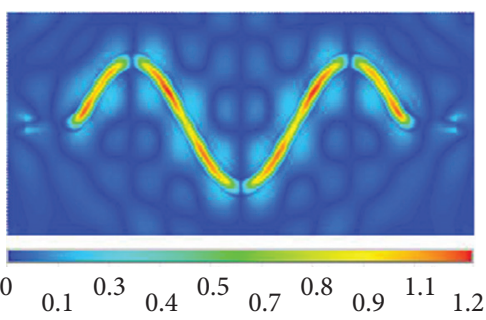

(b)

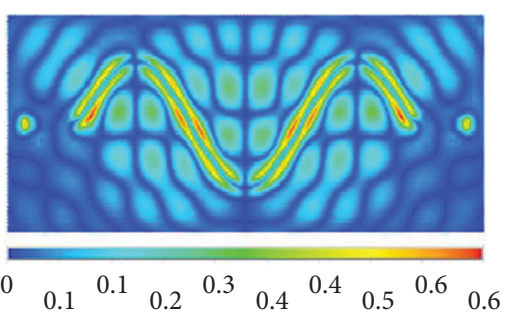

(c)

FiguRE 58: SV wave incident $\left(\mathrm{NR}=3, f=1.5 \mathrm{~Hz}, H=100 \mathrm{~m}\right.$, and $\left.C_{s}=500 \mathrm{~m} / \mathrm{s}\right)$. Top view displacement cloud view (a) $u_{x}$, (b) $u_{y}$, and (c) $u_{z}$.

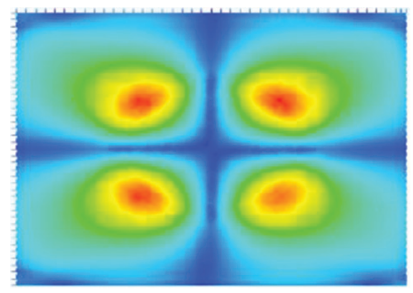

(a)

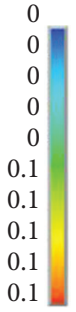

0.1

FIGURE 59: SH wave incident (3D sedimentary hemispheric basin, $f=1.5 \mathrm{~Hz}, R=100 \mathrm{~m}$, and $C_{\mathrm{s}}=500 \mathrm{~m} / \mathrm{s}$ ). Top view displacement cloud view (a) $u_{x}$, (b) $u_{y}$, and (c) $u_{z}$.

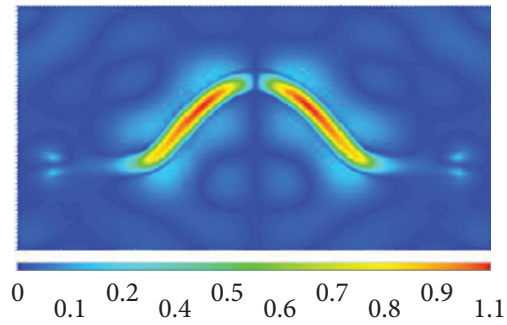

(a)

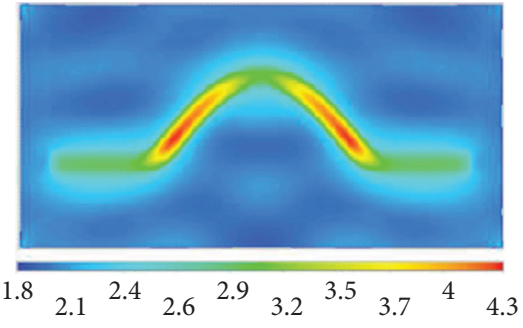

(b)

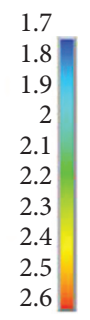

(b)

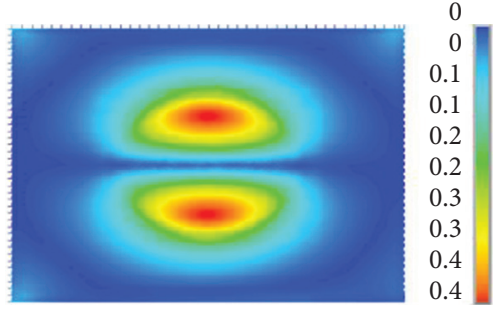

(c)

Figure 60: SH wave incident $\left(\mathrm{NR}=1, f=1.5 \mathrm{~Hz}, H=100 \mathrm{~m}\right.$, and $\left.C_{s}=500 \mathrm{~m} / \mathrm{s}\right)$. Top view displacement cloud view (a) $u_{x}$, (b) $u_{y}$, and (c) $u_{z}$.

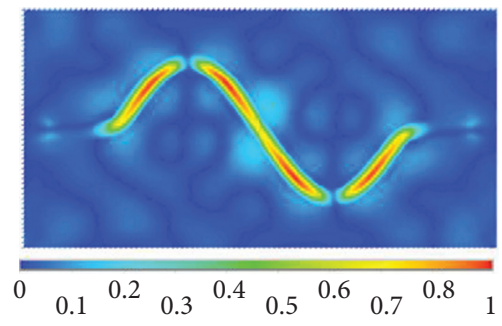

(a)

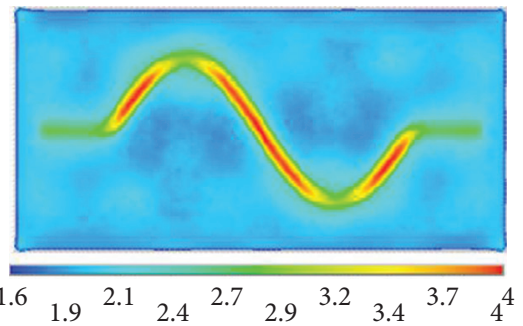

(b)

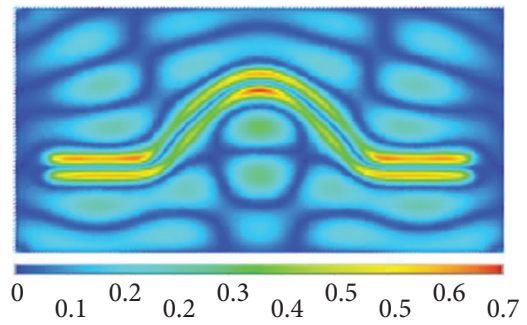

(c)

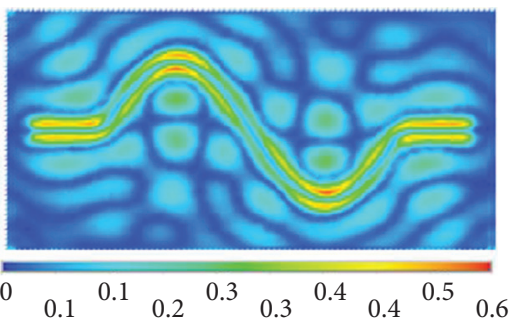

(c)

Figure 61: SH wave incident $\left(\mathrm{NR}=2, f=1.5 .0 \mathrm{~Hz}, H=100 \mathrm{~m}\right.$, and $\left.C_{s}=500 \mathrm{~m} / \mathrm{s}\right)$. Top view displacement cloud view (a) $u_{x}$, (b) $u_{y}$, and (c) $u_{z}$. 


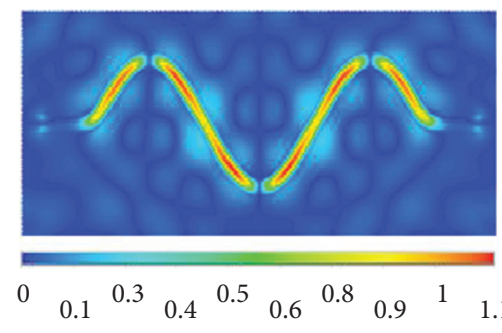

(a)

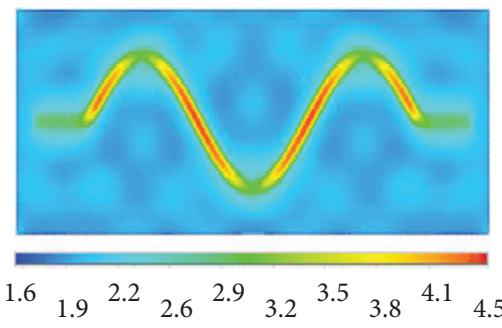

(b)

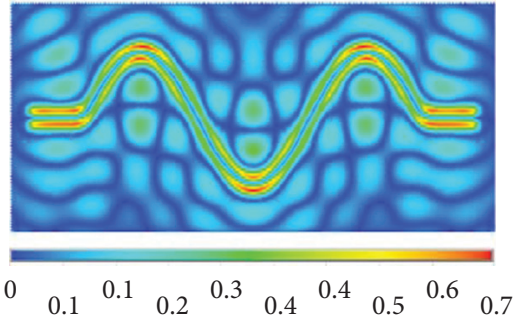

(c)

Figure 62: $\mathrm{SH}$ wave incident $\left(\mathrm{NR}=3, f=1.5 .0 \mathrm{~Hz}, H=100 \mathrm{~m}\right.$, and $\left.C_{\mathrm{s}}=500 \mathrm{~m} / \mathrm{s}\right)$. Top view displacement cloud view (a) $u_{x}$, (b) $u_{y}$, and (c) $u_{z}$.

\section{Conclusion}

In this study, a simplified three-dimensional sinuous meandering sedimentary valley was investigated using the harmonic response analysis of finite element analysis. It was verified that this method could effectively solve the frequency domain analysis of ground motion in a sedimentary valley. The study showed that, for vertical incidence of $\mathrm{P}$ wave, SV wave, and SH wave, seismic response of the threedimensional sedimentary valley meander is mainly determined by the incidence frequency $(f)$, the depth of deposition $(H)$, the sedimentary soil shear wave velocity, the number of meanders (NR), and so on.

(1) Compared with three-dimensional hemispheric sedimentary basins, the amplification effect of surface displacement amplitudes on three-dimensional meandering sedimentary valley sites is more significant. The amplification effect of surface displacement amplitudes in the main direction is about 2 times that in hemispheric sedimentary basins, the amplification effect of displacement amplitudes in the secondary direction is more obvious, and the maximum displacement amplitudes are about 12 times of that in hemispheric sedimentary basins. It is indicated that the amplification effect of ground motion should be paid special attention in large winding river valley site engineering.

(2) The results show that when the angle between the axis of the meandering valley and the vibration direction is small, it belongs to the obvious amplification area of ground motion, while when the axis of the meandering valley is basically vertical to the vibration direction, the amplification effect of ground motion is small and it belongs to the safe area of engineering construction. For the $\mathrm{P}$ wave, the displacement $U x$ in the main direction shows a significant amplification of the overall displacement of the meandering valley. For SV waves in sedimentary valleys, the displacement $U x$ in the main direction is obviously amplified in a certain range of meandering corners. The amplification effect of main direction displacement $U y$ on $\mathrm{SH}$ wave is more obvious in meandering valley section (except meandering corner).

(3) The weakening effect, with the increase of the number of meanders NR, was increasingly obvious in the vent area. The maximum reduction of surface displacement in the main direction is $73 \%$. At the junction of the straight section of the meandering sedimentary river valley site and the free site, the straight section had a significant boundary effect at the junction of the meandering section. The main direction displacement amplitude was $24 \%$ higher than the general displacement amplitude of the straight section due to the boundary effect. It is recommended that special attention be paid to this in future river valley projects.

(4) As the frequency of the incident wave approached the natural frequency of one direction, the displacement in this direction increased significantly, indicating that the resonance effect of the meandering sedimentary river valley site had a substantial effect on the displacement in one direction. For example, when $f=1.8 \mathrm{~Hz}$, the surface displacement amplitude in the main direction $(x$ direction) is close to 7.0. When the displacement in the main direction reached 7.0, it was near the natural frequency of the $z$-direction and the displacement in the $z$-direction of the secondary direction was as high as 5.6.

(5) With respect to the three influencing variables discussed in the study, the number of meanders NR was the main factor that affected the partial displacement reduction and the enlargement of the deposition site in the bend section. The low-frequency incident wave frequency $f$ and the deposition depth $H$ were the main factors that affected the amplitude of the surface displacement. The high-frequency incident wave frequency $f$ was the main factor that affected the transformation of the surface displacement characteristics [70-72].

\section{Data Availability}

The data used to support the findings of this study are available from the corresponding author upon request.

\section{Conflicts of Interest}

The authors declare that there are no potential conflicts of interest with respect to the research, authorship, and/or publication of this article. 


\section{Acknowledgments}

This study was supported by the Major Rail Transit Special Project in Tianjin, China (No. 18ZXGDGX00050), Tianjin Municipal Science and Technology Bureau (No. 19PTZWHZ00080), Tianjin Municipal Natural Science Foundation (No. 18JCZDJC10010), and Tianjin "Project+ Team" Key Training Project (2020), which the authors gratefully acknowledge.

\section{References}

[1] M. D. Trifunac, "Scattering of plane sh waves by a semi-cylindrical canyon," Earthquake Engineering \& Structural Dynamics, vol. 1, no. 3, pp. 267-281, 1972.

[2] M. Çelebi, "Topographical and geological amplifications determined from strong-motion and aftershock records of the 3 March 1985 Chile earthquake," Bulletin of the Seismological Society of America, vol. 77, no. 4, pp. 1147-1167, 1987.

[3] R. W. Graves, A. Pitarka, and P. G. Somerville, "Groundmotion amplification in the Santa Monica areapp Effects of shallow basin-edge structure," Bulletin of the Seismological Society of America, vol. 88, no. 5, pp. 1224-1242, 1998.

[4] E. Reinoso and M. Ordaz, "Spectral ratios for Mexico City from free-field recordings," Earthquake Spectra, vol. 15, no. 2, pp. 273-295, 1999.

[5] S. E. Hough, J. R. Altidor, D. Anglade et al., "Localized damage caused by topographic amplification during the 2010 M 7.0 Haiti earthquake," Nature Geoscience, vol. 3, no. 11, pp. $778-782,2010$.

[6] R. A. Green, S. M. Olson, B. R. Cox et al., "Geotechnical aspects of failures at Port-au-Prince seaport during the 12 January 2010 Haiti earthquake," Earthquake Spectra, vol. 27, no. S1, pp. S43-S65, 2011.

[7] K. Aki and K. L. Larner, "Surface motion of a layered medium having an irregular interface due to incident planeSHwaves," Journal of Geophysical Research, vol. 75, no. 5, pp. 933-954, 1970.

[8] V. W. Lee and W. Y. Liu, "Two-dimensional scattering and diffraction of $\mathrm{P}$ - and $\mathrm{SV}$-waves around a semi-circular canyon in an elastic half-space: an analytic solution via a stress-free wave function," Soil Dynamics and Earthquake Engineering, vol. 63, pp. 110-119, 2014.

[9] N. Zhang, Y. Zhang, Y. Gao, R. Y. S. Pak, Y. Wu, and F. Zhang, "An exact solution forSH-wave scattering by a radially multilayered inhomogeneous semicylindrical canyon," Geophysical Journal International, vol. 217, no. 2, pp. 1232-1260, 2019.

[10] Y. Gao, N. Zhang, D. Li, H. Liu, Y. Cai, and Y. Wu, "Effects of topographic amplification induced by a U-shaped canyon on seismic waves," Bulletin of the Seismological Society of America, vol. 102, no. 4, pp. 1748-1763, 2012.

[11] Y. Gao and N. Zhang, "Scattering of cylindrical SH waves induced by a symmetrical V-shaped canyon: near-source topographic effects," Geophysical Journal International, vol. 193 , no. 2, pp. 874-885, 2013.

[12] K. H. Chang, D. H. Tsaur, and J. H. Wang, "Scattering of SH waves by a circular sectorial canyon," Geophysical Journal International, vol. 195, no. 1, pp. 532-543, 2013.

[13] J. W. Liang, L. J. Yan, and V. W. Lee, "Effects of a covering layer in a circular-arc canyon on incident plane SV waves," Acta Seismologica Sinica (English edition), vol. 14, no. 6, pp. 660-675, 2001.
[14] G. Liu, B. Ji, and D. Liu, "Analytical solution for ground motion of a half space with a semi-cylindrical canyon and a beeline crack. Proceedings of the Royal Society App Mathematical," Physical and Engineering Sciences, vol. 1, no. 3, pp. 1905-1921, 2008.

[15] D. H. Tsaur and K. H. Chang, "Scattering of SH waves by truncated semicircular canyon," Journal of Engineering Mechanics, vol. 135, no. 8, pp. 862-870, 2009.

[16] D. H. Tsaur, K. H. Chang, and M. S. Hsu, "An analytical approach for the scattering of $\mathrm{SH}$ waves by a symmetrical V-shaped canyon: deep case," Geophysical Journal International, vol. 183, no. 3, pp. 1501-1511, 2010.

[17] Y. Gao, "Analytical model of seismic wave propagation and amplification effect in River Valley," Journal of geotechnical engineering, vol. 41, no. 1, pp. 1-25, 2019, [in Chinese].

[18] P. Li, J. Bo, R. Xiao, and Y. Zhang, "A study on the influencing factors on ground motion in a valley site," Earthquake Research in China, vol. 33, no. 1, pp. 62-73, 2019.

[19] C. Zeng, J. Xia, R. D. Miller, and G. P. Tsoflias, “An improved vacuum formulation for $2 \mathrm{D}$ finite-difference modeling of Rayleigh waves including surface topography and internal discontinuities," Geophysics, vol. 77, no. 1, pp. T1-T9, 2012.

[20] J. Najafizadeh, M. Kamalian, M. K. Jafari, and N. Khaji, "Seismic analysis of rectangular alluvial valleys subjected to incident SV waves by using the spectral finite element method," International Journal of Civil Engineering, vol. 12, no. 3, pp. 251-263, 2014.

[21] P. Aminpour, J. Najafizadeh, M. Kamalian, and M. K. Jafari, "Seismic response of 2D triangular-shaped alluvial valleys to vertically propagating incident SV waves," Journal of Seismology and Earthquake Engineering, vol. 17, no. 2, pp. 89-101, 2015.

[22] Y. Pan, L. Gao, and T. Bohlen, "Time-domain full-waveform inversion of Rayleigh and Love waves in presence of freesurface topography," Journal of Applied Geophysics, vol. 152, pp. 77-85, 2018.

[23] A. Nohegoo-Shahvari, M. Kamalian, and M. Panji, "Twodimensional dynamic analysis of alluvial valleys subjected to vertically propagating incident SH waves," International Journal of Civil Engineering, vol. 17, no. 6, pp. 823-839, 2019.

[24] R. Vijaya, A. Boominathan, and I. Mazzieri, "3D ground response analysis of simplified kutch basin by spectral element method," Journal of Earthquake and Tsunami, vol. 14, no. 1, 2020.

[25] X. Yuan and Z. P. Liao, "Scattering of plane SH waves by a cylindrical canyon of circular-arc cross-section," Soil Dynamics and Earthquake Engineering, vol. 13, no. 6, pp. 407412, 1994.

[26] G. Liu, H. Chen, D. Liu, and B. C. Khoo, "Surface motion of a half-space with triangular and semicircular hills under incident SH waves," Bulletin of the Seismological Society of America, vol. 100, no. 3, pp. 1306-1319, 2010.

[27] M. Panji and S. H. Mojtabazadeh, "Transient response of irregular surface by periodically distributed semi-sine shaped valleyspp incident SH waves," Journal of Earthquake and Tsunami, vol. 14, no. 1, 2020.

[28] Z. Liu, J. Liang, and Y. Huang, "The IBIEM solution to the scattering of plane SV waves around a canyon in saturated poroelastic half-space," Journal of Earthquake Engineering, vol. 1, no. 6, pp. 956-977, 2015.

[29] Z. Liu, Z. Wang, L. Guo, D. Wang, and F. Wu, "A fast-multipole accelerated method of fundamental solutions for 2-D broadband scattering of SH waves in an infinite half space," Journal of Vibroengineering, vol. 21, no. 1, pp. 250-264, 2019. 
[30] Z. L. Yang, X. Z. Li, Y. Q. Song, G. X. X. Jiang, and Y. Yang, "Scattering of sh waves by a semi-cylindrical canyon in a radially inhomogeneous media," Waves In Random And Complex Media, vol. 2019, pp. 1-17, 2019.

[31] B. Gatmiri, D. B. Amini, O. Dorostkar, and M. R. Vakili, "Practical recommendations of spectral response analysis in non-curved alluvial valleys using hybrid FE/BE method," Journal of Multiscale Modelling, vol. 5, no. 2, 2013.

[32] L. Huang, Z. Liu, C. Wu, and J. Liang, "Interaction between a tunnel and alluvial valley under plane SV waves of earthquakes by IBIEM," European Journal of Environmental and Civil Engineering, vol. 4, pp. 1-19, 2019.

[33] J. Liang, Z. Liu, L. Huang, and G. Yang, "The indirect boundary integral equation method for the broadband scattering of plane P, SV and Rayleigh waves by a hill topography," Engineering Analysis with Boundary Elements, vol. 98, pp. 184-202, 2019.

[34] B. Gatmiri and C. Arson, "Seismic site effects by an optimized 2D BE/FE method II. Quantification of site effects in twodimensional sedimentary valleys," Soil Dynamics and Earthquake Engineering, vol. 28, no. 8, pp. 646-661, 2008.

[35] W. S. Shyu, T. J. Teng, and C. S. Chou, "Determining antiplane responses induced by oblique-truncated semicircular canyon using systematic hybrid method with mapping function," Soil Dynamics and Earthquake Engineering, vol. 77, pp. 24-34, 2015.

[36] Y. Yao, T. Liu, and J. M. Zhang, "A new series solution method for two-dimensional elastic wave scattering along a canyon in half-space," Soil Dynamics and Earthquake Engineering, vol. 89, pp. 128-135, 2016.

[37] B. Gatmiri, S. Le Pense, and P. Maghoul, "A multi-scale seismic response of two-dimensional sedimentary valleys due to the combined effects of topography and geology," Journal of Multiscale Modelling, vol. 3, no. 3, pp. 133-149, 2011.

[38] H. Zhou, "Review on the study of topographic effect on seismic ground motion," Earthquake Science, vol. 31, no. 1, pp. 1-7, 2018.

[39] T. K. Mossessian and M. Dravinski, "Amplification of elastic waves by a three dimensional valley. Part 1: s," Earthquake Engineering \& Structural Dynamics, vol. 19, no. 5, pp. 667$680,1990$.

[40] F. J. S. Sanchez and F. Luzon, "Seismic response of 3D alluvial valleys for incident $\mathrm{P}, \mathrm{S}$ and Rayleigh waves," Bulletin of the Seismological Society of America, vol. 85, no. 1, pp. 269-284, 1995.

[41] H. Takenaka, B. L. N. Kennett, and H. Fujiwara, "Effect of 2-D topography on the 3-D seismic wavefield using a $2.5-\mathrm{D}$ discrete wavenumber-boundary integral equation method," Geophysical Journal International, vol. 124, no. 3, pp. 741-755, 1996.

[42] J. F. Lu, D. S. Jeng, and S. Williams, "A 2.5-D dynamic model for a saturated porous medium: Part I. Green's function," International Journal of Solids and Structures, vol. 45, no. 2, pp. 378-391, 2008.

[43] B. Zhenning and L. Jianwen, " $2.5 \mathrm{D}$ scattering of incident plane SV waves by a canyon in layered half-space," Earthquake Engineering and Engineering Vibration, vol. 9, no. 4, pp. 587-595, 2010.

[44] B. A. Zhenning, Q. Sang, and V. W. Lee, " 2.5 D scattering of obliquely incident seismic waves due to a canyon cut in a multi-layered TI saturated half-space," Soil Dynamics and Earthquake Engineering, vol. 129, 2020.

[45] Z. Ba, Z. Fu, Z. Liu, and Q. Sang, "A 2.5D IBEM to investigate the $3 \mathrm{D}$ seismic response of $2 \mathrm{D}$ topographies in a multi-layered transversely isotropic half-space," Engineering Analysis with Boundary Elements, vol. 113, pp. 382-401, 2020.

[46] S. J. Lee, H. W. Chen, Q. Liu, D. Komatitsch, B. S. Huang, and J. Tromp, "Three-dimensional simulations of seismic wave propagation in the taipei basin with realistic topography based upon the spectral-element method," Bulletin of the Seismological Society of America, vol. 98, 1 page, 2008.

[47] S. K. Shani, M. Tsesarsky, J. N. Louie, and Z. Gvirtzman, "Simulation of seismic-wave propagation through geometrically complex basinspp the dead sea basin," Bulletin of the Seismological Society of America, vol. 102, no. 4, 2011.

[48] H. Yamanaka, "Estimation of 3D S-wave velocity model of deep sedimentary layers in Kanto-plain, Japan, using microtremor array measurements," Butsuri-Tansa, vol. 55, pp. 53-65, 2002.

[49] D. Komatitsch, Q. Liu, J. Tromp, P. Suss, C. Stidham, and J. H. Shaw, "Simulations of ground motion in the Los Angeles basin based upon the spectral-element method," Bulletin of the Seismological Society of America, vol. 94, no. 1, pp. 187206, 2004.

[50] S. Harmsen, S. Hartzell, and P. Liu, "Simulated ground motion in santa clara valley, California, and vicinity from $\mathrm{M}>=6.7$ scenario earthquakes," Bulletin of the Seismological Society of America, vol. 98, no. 3, pp. 1243-1271, 2008.

[51] T. Satoh, H. Kawase, T. Sato, and A. Pitarka, "Three-dimensional finite-difference waveform modeling of strong motions observed in the Sendai basin, Japan," Bulletin of the Seismological Society of America, vol. 91, no. 4, pp. 812-825, 2001.

[52] A. Frankel, W. Stephenson, and D. Carver, "sedimentary basin effects in seattle, Washington: ground-motion observations and 3D simulations," Bulletin of the Seismological Society of America, vol. 99, no. 3, pp. 1579-1611, 2009.

[53] S. J. Lee, H. W. Chen, and B. S. Huang, "Simulations of strong ground motion and $3 \mathrm{D}$ amplification effect in the Taipei Basin by using a composite grid finite-difference method," Bulletin of the Seismological Society of America, vol. 98, no. 3, pp. 1229-1242, 2008.

[54] A. Sommerfeld, M. Stern, G. Kuerti et al., Lectures on theoretical physics, Academic Press, N Y, USA, 1994.

[55] J. Lysmer and R. L. Kuhlemeyer, "Finite dynamic model for infinite media," Journal of the Engineering Mechanics Division, vol. 95, no. 4, pp. 859-877, 1969.

[56] W. D. Smith, "A noNReflecting plane boundary for wave propagation problems," Journal of Computational Physics, vol. 15 , no. 4, pp. 492-503, 1974.

[57] R. R. Kunar and J. Marti, "A Non-reflecting Boundary for Explicit Calculations," in Proceedings of the ASME 102nd Winter Annual Meeting of Computational Methods for Infinite Domain-Media Interaction, pp. 183-204, Washington D. C., USA, November 1981.

[58] J. Liu and B. Li, "A unified viscous-spring artificial boundary for 3-D static and dynamic applications," Science in China, Series A, vol. 48, no. 5, pp. 570-584, 2005.

[59] J. Liu, X. Bao, D. Wang, and P. Wang, "Seismic response analysis of the reef-seawater system under incident SV wave," Ocean Engineering, vol. 180, pp. 199-210, 2019.

[60] D. Lyu, S. Ma, C. Yu et al., "Effects of oblique incidence of SV waves on nonlinear seismic response of a lined arched tunnel," Shock and Vibration, vol. 2020, Article ID 8093804, 12 pages, 2020.

[61] R. L. Higdon, "Absorbing boundary conditions for acoustic and elastic waves in stratified media," Journal of Computational Physics, vol. 101, no. 2, pp. 386-418, 1992. 
[62] A. J. Deeks and M. F. Randolph, "Axisymmetric time-domain transmitting boundaries," Journal of Engineering Mechanics, vol. 120, no. 1, pp. 25-42, 1994.

[63] J. Liu, Y. Du, X. Du, Z. Wang, and J. Wu, “3D viscous-spring artificial boundary in time domain," Earthquake Engineering and Engineering Vibration, vol. 5, no. 1, pp. 93-102, 2006.

[64] M. Y. Bai, H. W. Wang, C. Shen, and K. Z. Xie, "Study on characteristics of ground motion in karst area based on viscoelastic artificial boundary," in Proceedings of the GeoShanghai 2018 International Conference: Tunnelling and Underground Construction, Springer, Shangai, China, May 2018.

[65] Z. P. Liao and H. L. Wong, "A transmitting boundary for the numerical simulation of elastic wave propagation," International Journal of Soil Dynamics and Earthquake Engineering, vol. 3, no. 4, pp. 174-183, 1984.

[66] P. Li and E.-x. Song, "A viscous-spring transmitting boundary for cylindrical wave propagation in saturated poroelastic media," Soil Dynamics and Earthquake Engineering, vol. 65, pp. 269-283, 2014.

[67] Y. Gu, J. Liu, and Y. Du, "3-D uniform viscoelasticity artificial boundary and viscoelasticity boundary element," Engineering Mechanics, vol. 24, no. 12, pp. 31-37, 2007.

[68] X. Zhou, Q. Liang, Y. Zhang, Z. Liu, and Y. He, “Three-dimensional nonlinear seismic response of immersed tunnel in horizontally layered site under obliquely incident SV waves," Shock and Vibration, vol. 2019, no. 3, 17 pages, Article ID 3131502, 2019.

[69] M. Dravinski and T. K. Mossessian, "Scattering of plane harmonic P, SV, and Rayleigh waves by dipping layers of arbitrary shape," Bulletin of the Seismological Society of America, vol. 77, no. 1, pp. 212-235, 1987.

[70] R. Clayton and B. Engquist, "Absorbing boundary conditions for acoustic and elastic wave equations," Bulletin of the Seismological Society of America, vol. 67, no. 6, pp. 1529-1540, 1977.

[71] B. Engquist and A. Majda, "Absorbing boundary conditions for numerical simulation of waves," Proceedings of the $\mathrm{Na}$ tional Academy of Sciences, vol. 74, no. 5, pp. 1765-1766, 1977.

[72] R. W. Clayton and B. Engquist, "Absorbing boundary conditions for wave-equation migration," Geophysics, vol. 45, no. 5, pp. 895-904, 1980. 